\title{
Italian association of clinical endocrinologists (AME) position statement: drug therapy of osteoporosis
}

\author{
F. Vescini ${ }^{1} \cdot$ R. Attanasio ${ }^{2}$ A. Balestrieri ${ }^{3} \cdot$ F. Bandeira $^{4} \cdot$ S. Bonadonna ${ }^{5}$.

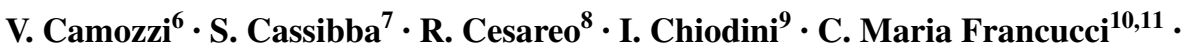 \\ L. Gianotti ${ }^{12}$ - F. Grimaldi ${ }^{1}$ R. Guglielmi ${ }^{13}$ - B. Madeo ${ }^{14} \cdot$ C. Marcocci $^{15}$. \\ A. Palermo ${ }^{16} \cdot$ A. Scillitani ${ }^{17} \cdot$ E. Vignali $^{18} \cdot$ V. Rochira ${ }^{19} \cdot$ M. Zini $^{20}$
}

Received: 28 September 2015 / Accepted: 22 January 2016 / Published online: 11 March 2016

(C) The Author(s) 2016. This article is published with open access at Springerlink.com

\begin{abstract}
Treatment of osteoporosis is aimed to prevent fragility fractures and to stabilize or increase bone mineral density. Several drugs with different efficacy and safety profiles are available. The long-term therapeutic strategy should be planned, and the initial treatment should be selected according to the individual site-specific fracture risk and the need to give the maximal protection when the fracture risk is highest (i.e. in the late life). The present consensus focused on the strategies for the treatment of postmenopausal osteoporosis taking into consideration all
\end{abstract}

Electronic supplementary material The online version of this article (doi:10.1007/s40618-016-0434-8) contains supplementary material, which is available to authorized users.

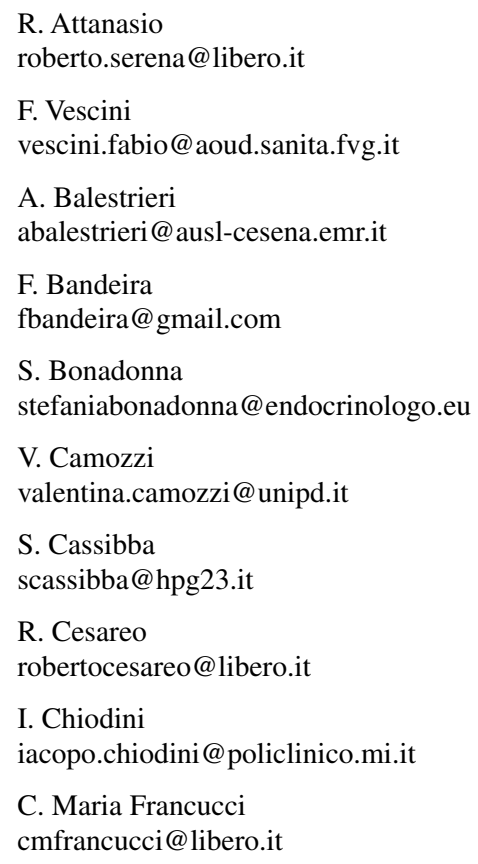

the drugs available for this purpose. A short revision of the literature about treatment of secondary osteoporosis due both to androgen deprivation therapy for prostate cancer and to aromatase inhibitors for breast cancer was also performed. Also premenopausal females and males with osteoporosis are frequently seen in endocrine settings. Finally particular attention was paid to the tailoring of treatment as well as to its duration.

\author{
L. Gianotti \\ laura.gianotti@unito.it \\ F. Grimaldi \\ grimaldi.franco@aoud.sanita.fvg.it \\ R. Guglielmi \\ rinaldo.guglielmi@gmail.com \\ B. Madeo \\ brunomadeo@hotmail.com \\ C. Marcocci \\ claudio.marcocci@med.unipi.it \\ A. Palermo \\ A.Palermo@unicampus.it \\ A. Scillitani \\ alscill@tin.it \\ E. Vignali \\ edda.vignali@tin.it \\ V. Rochira \\ rochira.vincenzo@unimore.it \\ M. Zini \\ michele.zini@asmn.re.it
}


Keywords Osteoporosis - Fracture $\cdot$ Treatment . Bisphosphonates $\cdot$ Teriparatide $\cdot$ Strontium ranelate . Denosumab - SERMs · Adherence $\cdot$ Side effects . Non-responder $\cdot$ Male osteoporosis $\cdot$ Drug-induced osteoporosis $\cdot$ Androgen deprivation $\cdot$ Aromatase inhibitors $\cdot$ Length of therapy

\section{Abbreviations}

$\begin{array}{ll}\text { AACE } & \begin{array}{l}\text { American Association of Clinical } \\ \text { Endocrinologists }\end{array} \\ \text { ADT } & \text { Androgen deprivation therapy } \\ \text { AFF } & \text { Atypical femoral fractures } \\ \text { AI } & \text { Aromatase inhibitors } \\ \text { BC } & \text { Breast cancer } \\ \text { BMD } & \text { Bone mineral density } \\ \text { BMI } & \text { Body mass index } \\ \text { BP } & \text { Bisphosphonate } \\ \text { BSAP } & \text { Bone-specific alkaline phosphatase } \\ \text { BTM } & \text { Bone turnover marker }\end{array}$

1 Endocrinology and Metabolic Disease Unit, Azienda Ospedaliero-Universitaria Santa Maria della Misericordia, P.le S.M. della Misericordia, 15, 33100 Udine, Italy

2 Endocrinology Service, Galeazzi Institute IRCCS, Milan, Italy

3 Unit of Endocrinology and Diabetology, Department of Internal Medicine, M. Bufalini Hospital, Cesena, Italy

4 Division of Endocrinology, Diabetes and Bone Diseases, Agamenon Magalhães Hospital, University of Pernambuco Medical School, Recife, Brazil

5 Istituto Auxologico Italiano, Milan, Italy

6 Unit of Endocrinology, Department of Medicine, University of Padova, Padua, Italy

7 Endocrinology and Diabetology, Papa Giovanni XXIII Hospital, Bergamo, Italy

8 Endocrinology, S. Maria Goretti Hospital, Latina, Italy

9 Department of Clinical Sciences and Community Health, University of Milan, Milan, Italy

10 Post Acute and Long Term Care Department, I.N.R.C.A., Ancona, Italy

11 San Pier Damiano Hospital, Villa Maria Group Care and Research, Faenza, Ravenna, Italy

12 Endocrinology and Metabolic Diseases, S. Croce e Carle Hospital, Cuneo, Italy

13 Endocrinology Unit, Regina Apostolorum Hospital, Albano Laziale, Rome, Italy

14 Integrated Department of Medicine, Endocrinology and Metabolism, Geriatrics, University of Modena and Reggio Emilia, Modena, Italy

15 Endocrine Unit 2, Department of Clinical and Experimental Medicine, University Hospital of Pisa, Pisa, Italy

16 Department of Endocrinology and Diabetes, University Campus Bio-Medico, Rome, Italy

$\begin{array}{ll}\text { CHD } & \text { Coronary heart disease } \\ \text { CI } & \text { Confidence interval } \\ \text { CTX } & \text { Collagen type I C-telopeptide } \\ \text { DeFRA } & \text { Derived fracture risk assessment tool } \\ \text { DEXA } & \text { Dual energy X-ray absorptiometry } \\ \text { ET } & \text { Estrogen therapy } \\ \text { EPT } & \text { Estrogen plus progestin therapy } \\ \text { FIT } & \text { Fracture intervention trial } \\ \text { FLEX } & \text { FIT long-term Extension } \\ \text { FN } & \text { Femoral neck } \\ \text { FRAX } & \text { Fracture risk assessment tool } \\ \text { GFR } & \text { Glomerular filtration rate } \\ \text { GIO } & \text { Glucocorticoid-induced osteoporosis } \\ \text { GnRH } & \text { Gonadotropin-releasing hormone } \\ \text { GRADE } & \text { Grading of recommendations, assessment, } \\ & \text { development, and evaluation } \\ \text { HIV } & \text { Human immunodeficiency virus } \\ \text { HT } & \text { Hormone therapy } \\ \text { IV } & \text { Intravenous } \\ \text { LoE } & \text { Level of evidence } \\ \text { LS } & \text { Lumbar spine } \\ \text { LSC } & \text { Least significant change } \\ \text { MPA } & \text { Medroxyprogesterone acetate } \\ \text { ONJ } & \text { Osteonecrosis of the jaw } \\ \text { OR } & \text { Odds ratio } \\ \text { P1NP } & \text { N-terminal propeptide of procollagen type 1 } \\ \text { PMO } & \text { Postmenopausal osteoporosis } \\ \text { PTH } & \text { Parathyroid hormone } \\ \text { RANK } & \text { Receptor activator of nuclear factor kappa B } \\ \text { RANK-L } & \text { RANK ligand } \\ \text { RCT } & \text { Randomized controlled trial } \\ \text { RR } & \text { Relative risk } \\ \text { SD } & \text { Standard deviation } \\ \text { SERM } & \text { Selective estrogen receptor modulator } \\ \text { SrR } & \text { Strontium ranelate } \\ \text { SC } & \text { Subcutaneous } \\ \text { T } & \text { Testosterone } \\ \text { TH } & \text { Total hip } \\ \text { WHI } & \text { Women's health initiative } \\ \text { WHO } & \text { World Health Organization } \\ & \end{array}$

17 Endocrinology, Casa Sollievo della Sofferenza IRCCS, San Giovanni Rotondo, Italy

18 Department of Clinical and Experimental Medicine, University Hospital of Pisa, Pisa, Italy

19 Unit of Endocrinology, Department of Biomedical, Metabolic and Neural Sciences, University of Modena and Reggio Emilia, Modena, Italy

20 Endocrinology Unit, Arcispedale S. Maria Nuova IRCCS, Reggio Emilia, Italy 


\begin{tabular}{lc}
\hline Table of contents & $\begin{array}{c}\text { Monitoring the effectiveness of } \\
\text { treatment } \\
\text { Abstract }\end{array}$ \\
$\begin{array}{l}\text { Bone turnover markers } \\
\text { Bntroduction }\end{array}$ \\
$\begin{array}{l}\text { Methodology } \\
\text { Postmenopausal osteoporosis }\end{array}$ & $\begin{array}{c}\text { Conducting the treatment } \\
\text { Whom to treat }\end{array}$ \\
Risk factors & Defining a non-responder \\
Treatment thresholds and indi- & Drug switch \\
cations to treatment & Adherence \\
How to treat & Other forms of osteoporosis \\
Available drugs & Male osteoporosis \\
Bisphosphonates & Androgen deprivation therapy \\
Alendronate & Premenopausal osteoporosis \\
Risedronate & Aromatase inhibitors \\
Ibandronate & Conclusions \\
Zoledronate & References \\
Clodronate & \\
Strontium ranelate & \\
Denosumab & \\
SERMs & \\
Hormone therapy & \\
Teriparatide & \\
\hline
\end{tabular}

\section{Introduction}

The goals of treatment of osteoporosis are to prevent fragility fractures and to stabilize or increase bone mineral density (BMD). Several drugs with different efficacy and safety profiles are now available, but no drug can be indefinitely used once started. The long-term therapeutic strategy should be planned, and the initial treatment selected according to the individual site-specific fracture risk when therapy is started and the need to give the maximal protection when the fracture risk is highest (i.e. later in life).

Regardless of the drug used, adequate calcium intake and vitamin D status are prerequisites of any osteoporosis prevention and treatment program [1].

The aim of the present consensus was mainly to review the available literature on the drug treatment of postmenopausal osteoporosis (PMO); some particular forms of secondary osteoporosis were reviewed as well. Our purpose was to provide endocrinologists with an easy tool for the management of osteoporotic patients in their clinical practice, thus we did not address epidemiology, classification, pathogenesis.

\section{Methodology}

The methodology of the present Consensus is based upon the Grading of Recommendations, Assessment, Development, and Evaluation (GRADE) system [2-4].
According to the GRADE system, the evidence quality is categorized as high, moderate, low, or very low. High quality evidence is defined as consistent evidence from well-performed randomized controlled trials (RCT) or exceptionally strong evidence from unbiased observational studies. Moderate quality evidence is evidence from RCTs with important limitations (inconsistent results, methodological flaws, indirect or imprecise evidence), or unusually strong evidence from unbiased observational studies. Low-quality evidence derives from observational studies, from RCTs with serious flaws, or indirect evidence. Very low-quality evidence stems from unsystematic clinical observations or very indirect evidence.

The GRADE system classifies the strength of recommendations into two grades (strong or weak). Strong recommendations (terminology: "we recommend") mean that benefits clearly outweigh harms and burdens, or vice versa. Weak recommendations (terminology: "we suggest") mean that the desirable effects of adherence to a recommendation probably outweigh the undesirable effects, but the panel is not confident.

Basically, high-level evidence supports strong recommendations, whereas biased or low-quality evidences generate weak recommendations. However, making recommendations for practice purposes require taking into account other factors, such as patients' values and preferences, local circumstances, and clinical expertise. As a consequence, the strength of a recommendation can be downgraded (weak recommendation generated by high or moderate quality evidence) or upgraded (strong recommendation generated from low or very low-quality evidence). The GRADE system formally recognizes this possibility. For example, poor quality of planning of a study suggesting high likelihood of bias, inconsistency of results, indirectness of evidence, surrogate or weak end-points, lack of precision with large confidence intervals may induce the panel to reduce the strength of a recommendation based upon an RCT. Vice versa, a recommendation based upon observational studies can be upgraded in case of large magnitude of effect, good quality of the study, long follow-up, large cohorts of patients.

\section{Postmenopausal osteoporosis (PMO)}

\section{Whom to treat}

\section{Risk factors}

To prevent the fracture, any fracture risk should be evaluated in the individual patient, adjusting all the modifiable ones $[5,6]$ (table I in supplemental material). 
$B M D$ is the major risk factor especially in over 65 -year women. A decrease in BMD of about 1 SD represents an increased risk factor ranging from 1.5 to 2.5 , depending mostly on the capacity of the BMD to predict the fracture risk on the same site. This relationship decreases with age, especially for hip fracture [7].

Puberty is a crucial period characterized by bone mass acquisition. Any adverse event affecting puberty directly (e.g. delayed puberty, hypogonadism) or indirectly (e.g. anorexia nervosa, starvation, excess physical activity) might permanently compromise peak bone mass acquisition both quantitative and qualitative [7-9].

Aging makes risk fracture increase, especially at the hip. Over 50 years, postmenopausal women double the risk of fractures every 7 or 8 years, being 70 and 82 years the median age for vertebral fracture and hip fracture, respectively [10]. In men, the risk of fractures increases later, becoming clinically relevant after $65-70$ years $[11,12]$.

Genetic factors seem to be the principal determinants in peak bone mass. Patients whose first-degree relatives are osteoporotic or suffered prior fracture have a lower BMD and increased fracture risk [13].

A prior osteoporotic fracture induces an increased risk for future fractures: prior forearm fracture is associated with a twofold increased risk of another fracture [14] and the risk of future vertebral deformities over 3 years is fivefold higher in patients with prior deformities. The risk of recurrent fracture is higher as the number of preexisting fractures increases, regardless of BMD adjusting.

Low body mass index (BMI $<18 \mathrm{~kg} / \mathrm{m}^{2}$ ) is a risk factor for low BMD, and, in older women, thinness is associated with increased fracture risk [15].

Several lifestyle factors negatively affect BMD and fracture risk: cigarette smoking, heavy alcohol consumption, absence of physical activity, low calcium and/or vitamin D intake, high caffeine intake [16].

The reduction of estrogens after menopause increases bone resorption, mostly after 3-4 years. In the first 5-7 years after menopause bone loss is estimated to be about $10 \%$ at the spine, $5 \%$ at the femoral neck (FN), and $7 \%$ in the whole body. With aging, postmenopausal women also develop an increased fracture risk ratio. Women with early-onset menopause (before 40 years) are at greater risk of developing osteoporosis [17].

Secondary causes of fracture risk are specific medications and chronic or genetic diseases (table II in supplemental material) $[5,6]$.

Secondary osteoporosis occurs in almost two-thirds of men, more than half of premenopausal and perimenopausal women, and about one-fifth of postmenopausal women. It is essential to identify and manage any cause of secondary osteoporosis. Failure to do so may result in further bone loss despite pharmacologic intervention. A few exams, together with the history of the patient, can exclude up to $90 \%$ of secondary osteoporosis (table III in supplemental material) [18].

Recommendations
We recommend considering patient's age in order to
evaluate increased fracture risk
We recommend asking about previous fractures in
patient's first-degree relatives
We recommend asking about previous fractures in the
patient (including evaluation of vertebral osteoporotic
deformities)
We suggest considering low-weight as an increased
fracture risk
We suggest inquiring patient's past health status at the
time of puberty
We suggest inquiring patient's lifestyle habits
potentially impacting fracture risk (e.g. cigarette
smoking, heavy alcohol consumption, absence of
physical activity, low calcium intake, low vitamin D
intake, high caffeine intake)
We recommend evaluating BMD value as predictive of
fracture risk
We recommend evaluating BMD in women with an
early-onset menopause or in women with any other
fracture risk at the menopause onset
We recommend ruling out any secondary cause of
osteoporosis including medications and chronic
he recommend checking for signs and/or symptoms of
hypogonadism in men

\section{Treatment thresholds and indications to treatment}

Even though fracture risk is higher in osteoporotic women, the great bulk of fractures occur in the far largest population of osteopenic women [19]. Many osteoporotic patients with a prior fracture are not tested with a dual-energy $\mathrm{X}$-ray absorptiometry (DEXA) exam, even if these highrisk patients are most likely to benefit from osteoporosis treatment.

FRAX $^{\circledR}$, an algorithm approved by the WHO for estimating the 10-year risk probability of hip and other major osteoporotic fracture [20], should be the tool to identify those patients candidate to pharmacological intervention [21]. FRAX has been validated in different countries (Italy is validating DeFRA, a FRAX derived algorithm) but there is no universally accepted fracture risk level for osteoporosis pharmacological therapy. Therefore, intervention thresholds vary from country to country $[22,23]$, 
depending on treatment cost-effectiveness, reimbursement issues, and health care system [24, 25].

Guidelines from National Osteoporosis Foundation and American Association of Clinical Endocrinologists (AACE) continue to recommend treatment of patients with hip and vertebral fractures and those with a central DEXA T-score $\leq-2.5$, but since 2008 they also began to recommend treatment of patients with DEXA-based T-scores between -2.5 and -1 if they had 10-year hip fracture probability $\geq 3 \%$ or major osteoporotic-related fracture probability $\geq 20 \%[26,27]$.

In any clinical situation fracture risk should be assessed only if its evidence would influence the treatment [28].

\section{Recommendations}

We recommend assessing fracture risk in all postmenopausal women and in men over 50

We recommend education to a correct lifestyle in all persons with modifiable fracture risk factors

We suggest assessing 10-year fracture risk (with FRAX or DeFRA) and performing BMD assessment in all subjects with non-modifiable fracture risk factors

We suggest reassessing 10-year fracture risk (with FRAX or DeFRA) in all subjects with modifiable fracture risk factor after correcting lifestyle

We recommend considering for treatment all subjects with a BMD assessment T-score $\leq-2.5 \mathrm{SD}$

We recommend considering for treatment all subjects with a prior fragility fracture, regardless of BMD measurement

We recommend considering for treatment all subjects with DEXA-based T-scores between -2.5 and -1 SD and with an increased 10-year fracture risk evaluated with a fracture risk algorithm (FRAX or DeFRA)

\section{How to treat}

Since all the registration trials, demonstrating the effectiveness of therapies for osteoporosis, associated calcium and vitamin D to the active treatment, it is mandatory to include calcium and vitamin D in every pharmacological treatment strategy.

\section{Available drugs}

Table 1 lists the drugs commonly used in the treatment of osteoporosis. Etidronate and calcitonin are still on the market, but are not included due to their scarce use.
Table 1 Approved drugs for osteoporosis

\begin{tabular}{llll}
\hline Class & Molecule & Oral & Injectable \\
\hline Bisphosphonates & Alendronate & $\times$ & \\
& Risedronate & $\times$ & \\
& Ibandronate & $\times$ & $\times$ \\
& Zoledronate & & $\times$ \\
& Clodronate & $\times$ & $\times$ \\
Strontium ranelate & & $\times$ & \\
Anti-RANKL antibody & Denosumab & & $\times$ \\
SERMs & Raloxifene & $\times$ & \\
& Bazedoxifene & $\times$ & \\
& Lasofoxifene & $\times$ & \\
Hormone therapy & Estrogens $( \pm$ progestins $)$ & $\times$ & \\
PTH analogs & Teriparatide & & $\times$ \\
\hline
\end{tabular}

Bisphosphonates (BPs) BPs attach to hydroxyapatite binding sites on bone surfaces where they are taken up by osteoclasts during bone resorption. Inside osteoclasts BPs inhibit the farnesyl-pyrophosphate synthase, and impair their ability to form a ruffled border, to adhere to the bone surface and produce protons, thus inducing osteoclasts apoptosis and inhibition of bone resorption [29, 30].

All oral BPs may induce gastrointestinal adverse events, including dyspepsia, dysphagia, and esophageal ulcers [31]. Among tablet formulations it is hypothesized that branded compounds are better tolerate than generics, likely due to differences in the technical production process or in the formulation of excipients [32].

The safety of long-term BPs therapy is unclear. Postmarketing reports of rare but serious adverse events, likely associated with prolonged therapy, such as atypical femoral fractures (AFF), osteonecrosis of the jaws (ONJ) and esophageal cancer, prompted the Food and Drug Administration to perform a systematic review of long-term efficacy and safety of these drugs. Data were conflicting and the committee did not support a regulatory restriction on the duration of drug use [33, 34].

Alendronate Alendronate increases BMD and reduces the risk of vertebral and non-vertebral fractures at 3-4 years in women with PMO defined as either having existing vertebral fracture or FN T-score $\leq-2.5[35,36]$.

The risk reduction rate is highly significant $(p<0.001)$ for radiologic vertebral fractures (48\%), multiple radiologic vertebral fractures $(87 \%)$, any clinical fracture $(30 \%)$, and any non-vertebral clinical fracture $(27 \%)$. Risk of hip fracture is reduced by $53 \%(p<0.005)$, clinical vertebral fracture by $45 \%(p<0.003)$, and wrist fracture by $30 \%(p<0.038)$. The reduction in risk is apparent since the first year of treatment for clinical vertebral fractures 
and for any clinical fracture, by month 18 for hip fracture, by month 24 for non-vertebral fracture and by month 30 for wrist fracture [36].

There are few available data for assessing the efficacy of long-term BP use. The evidence regarding continuing treatment beyond 5 years [37] demonstrates that from 5 to 10 -year treatment with alendronate leads to a continuous increase in vertebral BMD, stabilization of femoral BMD, and a reduction of incident clinical (symptomatic) vertebral fractures (RR 0.45 ; $95 \%$ CI 0.24-0.85). No evidence exists on the overall reduction in non-vertebral fractures, due to the limited size of the extension trial and the small numbers of fractures [33, 37].

Data from the FLEX study suggest that patients with low FN BMD (T-score <-2.5) after 3-5 years of treatment with alendronate and those with an existing vertebral fracture show the highest risk for future vertebral fractures, while patients with a FN T-score $>-2.0$ or without vertebral fracture have a lower risk degree [33, 37].

Alendronate has been licensed in Europe as oral formulation (tablets of $10 \mathrm{mg} /$ day and $70 \mathrm{mg} /$ week) and, more recently, as a drinkable solution and effervescent formulation [31].

Risedronate In women with PMO 3 years of $5 \mathrm{mg} / \mathrm{day}$ risedronate significantly reduced the risk of vertebral fracture ( -41 to $49 \%)$ in two placebo-controlled RCTs [38, 39] since the first year of therapy. It remained reduced through 7 years of treatment [40, 41], although studies did not include a placebo group after 5 years.

Two studies evaluated the effect of risedronate therapy on the risk of non-vertebral fracture: an RCT reported a $39 \%$ reduction [42], while the $33 \%$ reduction reported in the other study was not statistically significant versus placebo [39].

In an RCT enrolling 5445 postmenopausal women (age range $70-79$ years $)$, risedronate $(5 \mathrm{mg} /$ day) reduced the hip fracture risk by $40 \%$ in women with a densitometric diagnosis of osteoporosis, and by $60 \%$ in the subgroup with prior vertebral fractures, though the latter result derives from a post hoc analysis [43].

A 2-year RCT on early postmenopausal non-osteoporotic women (mean age, 51-52 years) showed that risedronate $(5 \mathrm{mg} /$ day) led to a significant BMD increase at lumbar spine (LS, $+5.7 \%$ ) and femur (+5.4\%) [42].

In older postmenopausal women, lumbar and femoral BMD increased significantly $(+4.3$ and $+2.8 \%$, respectively) after 3 years of risedronate therapy $(5 \mathrm{mg} /$ day) as compared with placebo-treated matched controls [38].
Risedronate therapy for 7 years increased BMD by $11.5 \%$ from baseline [41].

Risedronate has been approved in Europe for the treatment of PMO in oral tablets $(5 \mathrm{mg} /$ day, $35 \mathrm{mg} /$ weekly and $75 \mathrm{mg}$ on 2 consecutive days once a month).

Ibandronate In a 3-year placebo-controlled study on postmenopausal women (mean age 69 years) with low spinal BMD and vertebral fractures, oral ibandronate $(2.5 \mathrm{mg} /$ day) reduced significantly the risk of morphometric vertebral fracture by $52 \%$ but did not reduce the non-vertebral fracture risk in the overall study population. A post hoc analysis showed that the treatment might reduce $(-69 \%)$ the risk of non-vertebral fracture in the subgroup of patients with baseline FN T-scores <-3 [44].

Ibandronate significantly increased spinal and femoral BMD ( +5.2 and $+4.1 \%$, respectively) in postmenopausal women with low spinal BMD [44].

In early postmenopausal women (mean age 57.658.8 years) without osteoporosis a two-year treatment with oral ibandronate $(2.5 \mathrm{mg} /$ day $)$ led to a small, though significant, LS and hip BMD increase $(+1.9$ and $+1.2 \%$, respectively) [45].

No data are available on the effects of long-term ibandronate therapy.

Ibandronate is approved for the treatment of PMO both as a $150-\mathrm{mg}$ tablet once a month and as a $3-\mathrm{mg}$ intra-venous (IV) formulation every 3 months (not reimbursed in Italy).

Zoledronate Zoledronate is the most powerful BP: $60 \%$ is taken up by the skeleton after a 15-min IV infusion [46]. Once-yearly IV infusion of zoledronate $(5 \mathrm{mg}$ ), during a 3 -year period, significantly reduced the risk of vertebral, hip and non-vertebral fractures in women with PMO; moreover zoledronate increased BMD at all skeletal sites [47].

The infusion within 90 days after surgical repair of an osteoporotic hip fracture is associated with a reduction of new clinical fractures and improved global survival at 36 months [48].

Many patients can discontinue zoledronate after 3 years, but those at high risk of fracture may benefit by continuing treatment up to 6 years [49].

Flu-like symptoms may occur, particularly during the first administration. Paracetamol or ibuprofen alleviates post-dose symptoms that are commonly transient (lasting 1-3 days). In case of severity and persistence steroids may be helpful [50]. Gastrointestinal problems, local reaction at the injection site and uveitis are minor complications of zoledronate treatment. 
Concerns on cardiac action [47] were ruled out by clinical data that did not disclose significant difference in incidence of atrial fibrillation [51].

IV zoledronate is not recommended in subjects with severe renal impairment (creatinine clearance $<30 \mathrm{~mL}$ / min), but clinical trial showed that IV BPs did not result in long-term renal function decline [52].

ONJ is related to both the potency and duration of BP therapy. Occurrence of ONJ is rare in patients with osteoporosis who are receiving once-yearly zoledronate. Data from five clinical trials indicated that ONJ incidence is $<1$ in 14,200 treated patient per year [53].

The risk of AFF may rise with increasing duration of exposure to BPs (alendronate or risedronate) while in zoledronate-treated patients the risk is unknown [54].

Zoledronate $5 \mathrm{mg}$ IV yearly is approved for the treatment of PMO.

Clodronate A double-blind placebo-controlled trial proved the efficacy of $800 \mathrm{mg}$ daily oral clodronate both in increasing BMD and in reducing the incidence of single and multiple vertebral fractures in a group of women with PMO or secondary osteoporosis, with or without prior vertebral fractures [55]. Oral clodronate is also effective and comparable to other BPs in reducing all clinical fractures in elderly women, while it seems to be less effective on hip fractures [56].

A recent meta-analysis underlined the efficacy of clodronate in reducing the risk of new vertebral, non-vertebral and overall fractures but the majority of the data are from studies with oral clodronate [57].

Oral clodronate given at a dose of $1600 \mathrm{mg} / \mathrm{day}$, for at least 3 years, in women with normal BMD or with osteopenia affected by early stage breast cancer (BC) and treated with adjuvant chemotherapy or anti-estrogen treatment, increased BMD, with effects lasting for 7 years after treatment discontinuation [58].

Weekly $100 \mathrm{mg}$ intramuscular clodronate is registered in Italy for PMO treatment but it is not reimbursed. There are few low-quality studies concerning the effects of this formulation on fractures $[59,60]$.

Clodronate (generally at an oral daily dose of $1600 \mathrm{mg}$ ) is approved in patients with $\mathrm{BC}$ and it has been used also in subjects with myeloma and less frequently in other solid tumors with or without bone metastases [61].

Clodronate cannot be a real therapeutic option in Italy because oral formulation has no indication for PMO and at present it is not reimbursed by the Italian National Institute of Health.

\section{Recommendations}

We recommend the use of alendronate, risedronate, ibandronate or zoledronate to reduce the risk of vertebral fractures in women with PMO

We recommend the use of alendronate, ibandronate or zoledronate and suggest the use of risedronate to reduce the risk of non-vertebral fractures in women with $\mathrm{PMO}$

We recommend the use of risedronate or zoledronate and suggest the use of alendronate to reduce the risk of hip fractures in women with PMO

We recommend the use of alendronate, risedronate, ibandronate, or zoledronate to increase BMD in women with PMO

We suggest the use of oral clodronate in women with low BMD at risk for fractures

We suggest reevaluation and discontinuation of therapy in women who become low-risk (BMD T-score $>-2$ and/or absence of fractures at the time of reassessment) after a 3 to 5-year alendronate, or after a 5-year risedronate, or after a 3-year zoledronate treatment

In women who remain at high risk (T-score $\leq-2.5$ and the presence of fracture at the time of reassessment) after a 3 to 5-year BP treatment, we suggest the extension of therapy with alendronate up to 10 years, or with risedronate up to 7 years

We recommend the extension of therapy with zoledronate up to 6 years in women who remain at high risk after a 3-year treatment (T-score $\leq-2.5$ and the presence of fracture at the time of reassessment)

We suggest the use of weekly intramuscular $100 \mathrm{mg}$ clodronate in women with PMO when all other treatments cannot be used 
Strontium ranelate $(\mathrm{SrR})$ The mechanism of action of $\mathrm{SrR}$ is still not completely known, even though it seems to increase bone formation and reduce bone resorption [62-64].

SrR increases BMD and reduces the risk of vertebral and non-vertebral fractures at 3 and 5 years in women with PMO $[62,63]$. It reduces the relative risk of hip fractures in subjects older than 74 years and T-score $<-3$ [62]. Openlabel extension of these trials (up to 10 years) showed further increase in BMD [64].

SrR has been approved in Europe, as an oral 2-g daily formulation, for the prevention of vertebral and non-vertebral osteoporotic fractures in osteoporotic women.

$\mathrm{SrR}$ has been associated with an increased risk of venous thromboembolism and with rare cases of severe allergic skin reactions [65]. More recently, long-term post-approval surveillance safety analyses showed an increased cardiovascular risk in patients treated with SrR [66], though not confirmed by other analysis $[67,68]$. SrR is now contraindicated in patients with a history of cardiovascular and cerebrovascular disease, and uncontrolled hypertension [69]. Patients should be evaluated for cardiovascular risk before starting treatment with $\mathrm{SrR}$ and at regular intervals during treatment $[65,69]$.

\section{Recommendations \\ We suggest the use of SrR both in postmenopausal women and in men with severe osteoporosis and concomitant contraindications or intolerance to all the other available drugs \\ We recommend against the use of $\mathrm{SrR}$ in patients with previous or current venous thromboembolism or in those with temporary or permanent immobilization as well as in those subjects with uncontrolled hypertension, ischemic heart disease, obliterating arteriopathy of the lower limbs or cerebrovascular diseases}

Denosumab RANK ligand (RANKL) induces osteoclastogenesis by binding to its receptor (RANK). The interaction between RANKL and RANK can be blocked by a decoy receptor called osteoprotegerin, as well as by denosumab, a fully human antibody against RANKL. The effect of denosumab is the reduction of formation, function and survival of osteoclasts, which determines both a reduction of bone resorption and an increase of BMD. The drug is administered SC every 6 months. It is not cleared by kidneys, thus it can be used in patients with renal failure [70].

In PMO 36-month denosumab treatment reduced the incidence of vertebral, hip and non-vertebral fractures ( $-68,-40$, and $-20 \%$, respectively) [71]. Denosumab reduced the risk of vertebral, non-vertebral and hip fractures in patients older than 75 years $[72,73]$.

In the 5-year extension study denosumab induced gains in BMD at LS and total hip $(\mathrm{TH})(+13.7$ and $+7 \%$, respectively) [74]. In naïve-to-treatment PMO BMD increased more with denosumab than with alendronate [75], and in patients previously treated with BP the switch to denosumab induced a greater increase in BMD [76].

Denosumab is safe and well tolerated. Dermatological adverse events (i.e. dermatitis, rash, eczema, and in particular cellulitis and erysipelas) were more prevalent in treated patients than in placebo, although the number of events was very low $(0.3 \%)$. Hypocalcemia has been reported but not in patients assuming calcium and vitamin D. Few cases of ONJ and two of AFF have been reported, while there is no apparent increase of cancer or cardiovascular diseases.

\section{Recommendations}

We recommend the use of denosumab to reduce the risk of vertebral, non-vertebral and hip fractures in PMO

We recommend the use of denosumab to increase $\mathrm{BMD}$ in $\mathrm{PMO}$

We suggest the use of denosumab to increase BMD in osteoporotic men

Selective estrogen receptor modulators (SERMs) SERMs are non-steroidal compounds that bind to the estrogen receptor, acting as agonist or antagonist, depending on the target tissue.

Treatment with SERMs is associated with an increased frequency of hot flushes, leg cramps and venous thromboembolic events [77-80]. No adverse endometrial effect is observed with raloxifene and bazedoxifene [81], whereas an increased, but not clinically significant, endometrial thickness is associated to lasofoxifene [82].

Raloxifene (60 mg daily) is approved in the USA and Europe for the prevention and treatment of PMO. In a 3-year, placebo-controlled RCT in postmenopausal women with osteoporosis (T-score $<-2.5$ ) or low bone mass and prior vertebral fracture, raloxifene decreased the risk of new vertebral fractures by 50 and $30 \%$, respectively [77]. Raloxifene had no effect on the rate of non-vertebral and hip fracture [77]. Raloxifene showed effectiveness also in increasing BMD and reducing the risk of vertebral fractures in postmenopausal women with osteopenia [83].

Bazedoxifene (20 mg daily) is approved in Europe for the treatment of PMO in women at increased risk of fracture. In a 3-year placebo-controlled RCT in PMO, with or without prior vertebral fractures, bazedoxifene decreased the risk of new vertebral fractures by $42 \%$ [84]. In a 2-year 
extension of the study, bazedoxifene decreased the risk of new vertebral fractures by $35 \%$ [85]. Bazedoxifene had no effect on the rate of non-vertebral fracture and hip fracture. In a 2-year placebo-controlled RCT bazedoxifene associated with conjugated estrogen significantly increased BDM at the LS and hip [86].

Lasofoxifene ( $0.5 \mathrm{mg}$ daily) is approved in Europe for the treatment of PMO in women at increased risk of fracture. In a 5-year placebo-controlled RCT in PMO, lasofoxifene decreased the risk of new vertebral fractures and nonvertebral fractures by 42 and $24 \%$, respectively, but not hip fractures [77].

Recommendations
We recommend the use of raloxifene, bazedoxifene or
lasofoxifene to reduce the risk of vertebral fractures in
women with PMO
We suggest the use of lasofoxifene to reduce the risk of
non-vertebral fractures in women with PMO
We suggest the use of raloxifene, bazedoxifene or
lasofoxifene to increase BMD in women with PMO

Hormone therapy (HT) Estrogens reduce the accelerated bone turnover induced by menopause and prevent bone loss at all skeletal sites regardless of age and duration of therapy. The beneficial effects of systemic oral or transdermal estrogen therapy (ET) or estrogen plus progestin (EPT) for women with or without a uterus, respectively, on BMD preservation are established. RCTs indicated that standard doses of ET/EPT reduce spine and non-vertebral (including hip) fractures [87-89]. In the Million Women Study, when the overall fracture risk reduction was examined by type of hormone, no difference was found between ET and EPT [90]. Results were not influenced by sequential or continuous progestin use [90]. The RR of fracture was not different when specific estrogen or progestin products were compared (i.e. conjugated estrogens vs. estradiol; medroxyprogesterone acetate (MPA) vs. norethisterone or norgestrel/levonorgestrel) [90].

The benefits of HT on bone mass and fracture reduction dissipate quickly after discontinuation [91, 92], requiring the transition to a different treatment to preserve bone mass. In the Women's Health Initiative (WHI), women in the EPT/ET group who stopped HT for a few years had a rate of fractures equivalent to that of women assigned to placebo [91, 92]. The long-term risks of HT outweighed the benefits because systemic estrogen and MPA at standard doses for 5.6 years significantly increased risk of BC, stroke, coronary heart disease (CHD) and thromboembolic events [93-95]. In women who had undergone a hysterectomy, ET alone for 6.8 years resulted in a statistically significant increased risk of stroke and deep venous thrombosis, whereas BC, CHD, and pulmonary embolism were unchanged, suggesting a deleterious effect of MPA [96].

Recommendations
We recommend against the use of HT to reduce the risk
of fractures in PMO
We suggest a possible use of HT, rather than other bone-
specific treatments, in women experiencing an early
menopause who require prevention of bone loss until
they reach the normal age of menopause at which time
treatment should be reassessed

Teriparatide The 1-34 N-terminal fragment of PTH (teriparatide, $20 \mu \mathrm{g}$ daily by SC injection) is the only approved anabolic therapy for the management of PMO at increased risk of fracture [97]. The duration of treatment is limited to a maximum of 2 years.

Teriparatide is well tolerated, but nausea, pain in limbs, headache and dizziness were reported [98]. Contraindications to treatment include severe renal impairment (GFR $<30 \mathrm{~mL} / \mathrm{min}$ ), primary hyperparathyroidism, Paget's disease, unexplained elevation of alkaline phosphates, prior radiation therapy, skeletal malignancy, and bone metastases. The increased risk of osteosarcoma in rats was not confirmed for the relatively short-term use in humans [99].

In an RCT in women with prevalent vertebral fractures, teriparatide, compared with placebo, decreased the risk of new vertebral and non-vertebral fractures by 65 and $35 \%$, respectively, after a median 19-month treatment [100]. The beneficial effect on fracture risk persisted after discontinuation of therapy for 18 months for vertebral fractures and 30 months for non-vertebral fractures (both $40 \%$ reduction vs. placebo) [101, 102].

BP administration upon termination of teriparatide may strengthen the beneficial effect of therapy [101-103]. The efficacy of teriparatide may be variably attenuated by prior treatment with anti-resorptive drugs according to their potency [104-109].

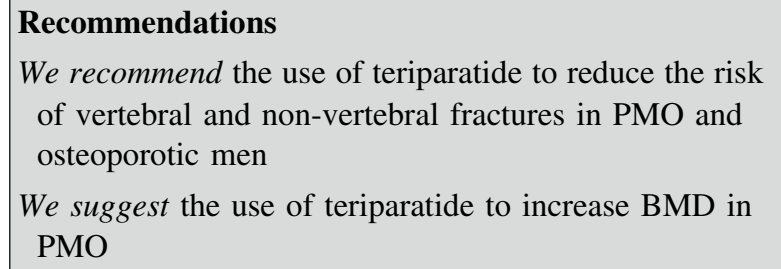
of vertebral and non-vertebral fractures in PMO and osteoporotic men

We suggest the use of teriparatide to increase BMD in PMO 
Table 2 Efficacy of different treatments on fracture risk in postmenopausal women (from 36, 38, 39, 42, 43, 44, 47, 48, 55, 62, 63, 71, $72,73,77,79,84,100)$

\begin{tabular}{llll}
\hline Drug & Vertebral & Non-vertebral & Hip \\
\hline Alendronate & + & + & + \\
Risedronate & + & + & + \\
Ibandronate & + & \pm & - \\
Zoledronate & + & + & + \\
Clodronate (800 mg/day, orally) & + & + & - \\
Strontium ranelate & + & + & \pm \\
Denosumab & + & + & + \\
Raloxifene & + & - & - \\
Bazedoxifene & + & \pm & - \\
Lasofoxifene & + & + & - \\
Teriparatide & + & + & - \\
\hline
\end{tabular}

Beware that results are not to be regarded as comparative between different drugs, since they are not derived from head to head studies

- no available data or negative data, \pm fracture risk decrease reported only in post hoc analyses, + fracture risk decreased vs. placebo

Table 2 summarizes the efficacy of different drugs on fracture risk in PMO.

\section{Monitoring the effectiveness of treatment}

Bone turnover markers (BTMs) BTMs may show a large and rapid response to the pharmacological treatment of osteoporosis. BTMs may offer an attractive monitoring strategy as they are non-invasive, relatively cheap, and able to detect changes in bone metabolism earlier than and independent from BMD variations [110]. As all studies have limitations due to significant pre-analytical and analytical variability of BMTs, the International Osteoporosis Foundation and the International Federation of Clinical Chemistry and Laboratory Medicine recommended the standardization of one marker of bone formation (if possible $\mathrm{N}$-terminal propeptide of procollagen type 1, P1NP) and one of bone resorption (if possible serum collagen type I C-telopeptide, CTX) [110].

Almost all the published studies focused on the effectiveness of BTMs in predicting BMD changes during osteoporosis therapy [111], but the strength of this association was poor $[112,113]$.

Scanty data correlated fracture risk reduction with variation of BTMs; weak evidence supports their role in monitoring anti-resorptive therapy [62,114-117], as well as in measuring fracture risk reduction during treatment with teriparatide or $\operatorname{SrR}[62,117]$. Nevertheless bone resorption markers seem to be more accurate than formation ones in predicting both bone loss rate and fracture risk reduction [118].
Evidence is still lacking about the threshold at which BTMs should be considered over-suppressed and potentially related with complications such as AFF.

\section{Recommendation \\ We recommend against routine use of BMTs in evaluating the effects of anti-osteoporosis drugs}

Bone mineral density $\mathrm{BMD}$ testing of central skeletal sites (spine and hip) by DEXA is considered the international standard for detecting osteoporosis, determining the risk of fracture, identifying the candidates to treatment and monitoring the efficacy of drugs. The goal of drug therapy for osteoporosis is to significantly increase bone strength, with BMD being one of the major determinants of this parameter [119], as well as to reduce fractures.

Changes in BMD reportedly account only for a small part of the fracture risk reduction seen in patients treated with anti-resorptive drugs [120]. In the FIT Study, spine BMD increase could explain only $16 \%$ of the risk reduction of vertebral fracture [112]. In patients treated with risedronate or raloxifene the changes in BMD correlated even more poorly with the degree of vertebral or non-vertebral fracture risk reduction. As a matter of fact patients taking risedronate, regardless whether their LS or hip BMD was increased or not, showed a similar incidence of non-vertebral fractures [121]. Similarly, raloxifene-induced BMD increase was able to explain only $4 \%$ of the observed vertebral fracture risk reduction, with the remaining $96 \%$ being unexplained [122]. A higher correlation was described for teriparatide, whose action on BMD could explain from 30 to $41 \%$ of vertebral fracture risk reduction [123].

More clear data were published on denosumab and SrR, suggesting that a larger proportion of their anti-fracture efficacy might be explained by changes in TH or FN BMD. A risk reduction up to $35 \%$ for new or worsening vertebral fractures and up to $87 \%$ for non-vertebral fractures can be explained by denosumab-induced increase of BMD [124]. SrR changes in hip and FN BMD have been correlated with a vertebral fracture risk reduction by 74 and $76 \%$, respectively [125].

BMD monitoring may help in identifying non-responder or non-compliant subjects; DEXA should be measured 1-2 years after starting or changing any anti-osteoporosis therapy [126]. These intervals are based both on the observed rates of change induced by anti-resorptive agents and on the reproducibility of DEXA testing. Once efficacy has been established, less frequent intervals between DEXA scans seem appropriate. 
Whether greater treatment-related changes in BMD result in greater decreases in fracture risk is controversial [127], but BMD testing alone seems to predictably underestimate the extent of fracture risk reduction induced by therapy. Other determinants of bone strength but BMD, like bone geometry, microarchitecture, remodeling rate, damage accumulation and collagen/mineral matrix properties, play an important role in reducing fracture risk.

\section{Recommendations \\ We suggest monitoring BMD changes induced by anti- osteoporosis therapy, even though they may underestimate the extent of fracture risk reduction \\ We recommend testing $\mathrm{BMD}$ at intervals not routinely shorter than 18-24 months and if possible in the same center with the same equipment to minimize variability}

\section{Conducting the treatment}

\section{Defining a non-responder}

A number of targets were proposed in osteoporosis treatment and this makes possible to assess a treatment failure $[128,129]$. BTMs and changes in BMD are the main candidates for these targets. Another controversial point is that, since drug therapy does not eliminate fracture risk, sustaining a single fracture during treatment should not be considered failure, as the risk of a new fracture decreases significantly during the treatment $[130,131]$.

Regarding BTMs, in a post hoc analysis of the FIT study, osteoporotic women with higher baseline levels of P1NP, CTX and bone-specific alkaline phosphatase (BSAP) showed a greater reduction in risk of non-vertebral (but not vertebral) fractures in response to alendronate than those with low levels [132]. Major reductions in one or more BTMs were reportedly associated with substantial reductions in vertebral, non-vertebral and hip fractures in women treated with alendronate [114]: the greater the reduction in BTMs, the lower is the risk of fracture. FIT study showed that women in the alendronate group, with a reduction of at least $30 \%$ of BSAP, had a lower risk of non-vertebral and hip fractures. This effect was just as strong as the anti-fracture effect observed with changes in BMD after 1 year [114]. A $<25 \%$ fall in serum CTX (the least significant change, LSC, at $95 \%$ confidence) on an anti-resorptive drug or teriparatide should be considered a treatment failure [110].

Much more controversy exists in relation to target BMD values during osteoporosis treatment. Some studies suggested that even patients with a decline in BMD might still benefit from oral BP therapy [133]. In clinical trials of alendronate, risedronate, and ibandronate, $8-25 \%$ of patients had BMD change $\leq 0 \%$ at the LS after 2 years of treatment. Post hoc analyses suggested that patients who experienced an increase in BMD had a lower vertebral fracture risk than those with a decline in BMD (range 38-50 \%). Additional analyses suggested that patients who experienced a decline in BMD while receiving oral BP therapy still appeared to receive some benefit (fracture risk reduction, 38-60 \%) from the treatment compared with those on a placebo [133]. It may, therefore, be difficult to tell a patient on BP treatment with a declining BMD over time that he/she has really lost his/her protection against osteoporotic fractures. Thus, a decline in BMD $\geq 5 \%$ at the LS and $\geq 4 \%$ at the FN (corresponding to LSC at $95 \%$ confidence) or a new fragility fracture should be considered treatment failure, as well as a reduction in serum CTX on anti-resorptive drugs or an increase on teriparatide smaller than LSC for the used marker.

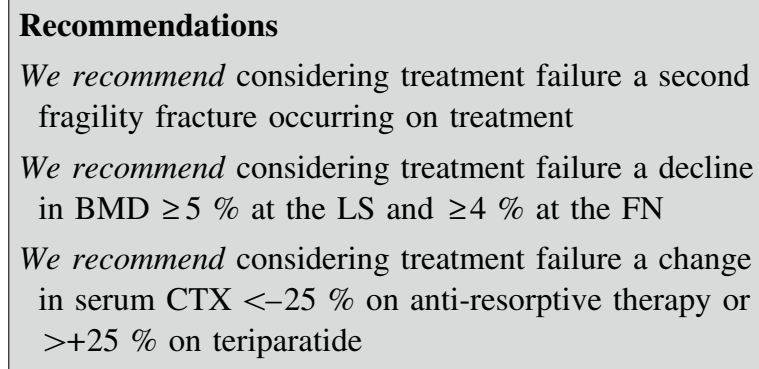

We recommend considering treatment failure a decline in BMD $\geq 5 \%$ at the $\mathrm{LS}$ and $\geq 4 \%$ at the FN

We recommend considering treatment failure a change in serum CTX $<-25 \%$ on anti-resorptive therapy or $>+25 \%$ on teriparatide

\section{How long to treat}

BPs continue to be the first-line agents to treat osteoporosis due to their efficacy, low cost, possible extra-skeletal effects [134], and the possibility of a residual effect following cessation of therapy $[37,49]$. On the other hand, BPassociated AFF, although rare, may cause a considerable impact on the patient's quality of life and should also be considered in planning when to stop or change therapy [54, 135-137]. This is mainly due to the fact that after 5 years of $\mathrm{BP}$ treatment, there is a sharp increase from 0.13 to $0.22 \%$ in the risk of AFF [136].

There are extension studies on alendronate, zoledronate and risedronate showing that patients may experience a residual effect after stopping therapy ("drug holiday") [37, 41, 49]. The benefit of continuing alendronate beyond 5 years has been observed for clinical vertebral fracture only [37]. Taken together, the rates of osteoporotic fractures were similar in patients who continued or stopped alendronate after a 5-year treatment [138]. On the other hand, a post hoc analysis demonstrated that patients with 
both no prevalent vertebral fracture at the start of FLEX trial and a BMD T-score $\leq-2.5$ would derive much more benefit in continuing therapy as regards clinical vertebral fracture risk reduction (number needed to treat in 5 years: 24) [33]. Likewise, women with a prevalent vertebral fracture at the start of FLEX trial and a BMD T-score $\leq-2.0$ derived a greater benefit when remaining on alendronate [33]. Women who were on $5 \mathrm{mg}$ /day during FLEX study had a similar benefit to those on a 10-mg dose, suggesting that alendronate doses of less than $70 \mathrm{mg}$ per week might be considered for treatment beyond 5 years [33].

The anti-fracture efficacy of risedronate was maintained for up to 7 years of treatment, and women who switched from placebo to risedronate at 5 years significantly decreased the incidence of vertebral fractures during the sixth and seventh years [41]. An extension study with zoledronate beyond 3 years showed that women who continued annual infusions for up to 6 years had a $49 \%$ reduction in the risk of morphometric vertebral fractures compared with those who stopped at 3 years [49]. Women with a FN T-score at 3 years $\leq-2.5$ benefited much more from continuing treatment for 6 years [49].

\begin{tabular}{|l|} 
Recommendations \\
We recommend continuing therapy in patients with no \\
prevalent vertebral fracture, after 5 years on oral \\
alendronate or risedronate and a T-score BMD $\leq-2.5$ \\
We recommend continuing therapy in patients with a \\
prevalent vertebral fracture, after 5 years on oral \\
alendronate or risedronate and a T-score BMD $\leq-2.0$ \\
We suggest considering the possible use of oral \\
alendronate doses lower than 70 mg per week for \\
treatment beyond 5 years \\
We recommend continuing annual infusions of \\
zoledronate for up to 6 years in patients with a \\
prevalent vertebral fracture, or in patients without \\
prevalent fractures but with a FN T-score at 3 years \\
$\leq-2.5$
\end{tabular}

\section{Drug switch}

In the high-risk patient one alternative is to change therapy to a class of osteoporosis medication with no pure antiresorptive effect or an osteoanabolic one, that is, $\mathrm{SrR}$ or teriparatide, respectively [139-142].

Postmenopausal women switched to SrR after longterm BP use showed different responses in BTMs in comparison to women who never used them [139-141]. There were short-term increases in serum CTX and osteocalcin [139] associated with long-term increases in BMD [140].
During the first 6 months of SrR therapy, there was a blunting of BMD response in patients previously treated with BPs compared to those who were not previously exposed to BPs. However, in the long term, they found a catch-up of BMD in those patients, along with an increase in BTMs (CTX, P1NP, and BSAP) [141].

The anti-fracture efficacy of teriparatide was compared in patients previously exposed to long-term BPs with those who had never used BPs. They were treated with teriparatide for 18 months and followed up for 36 months. All fractures decreased in both groups and this was maintained in the observation period, in which $70 \%$ of patients were on BPs. Back pain and quality of life improved in both groups, but these improvements were more pronounced in those patients with no prior BP use [142].

Since teriparatide administration is limited to 2 years and BMD starts to decrease shortly after its discontinuation, sequential therapy with anti-resorptive agents after teriparatide treatment is highly recommended although the benefit in terms of fracture risk reduction is speculative [27]. Alendronate [143] and, even more, zoledronate [144] and denosumab [145] after teriparatide are associated with a further increase in BMD. Also raloxifene maintains spine BMD and increases hip BMD after teriparatide discontinuation [146].

Not all the patients treated with BPs can be switched to teriparatide due to the high cost of this therapy. A double-blind, double-dummy RCT investigated the effects of switching to denosumab 504 postmenopausal women who had been receiving alendronate therapy for at least 6 months. Transition to denosumab produced greater increases in BMD at all measured skeletal sites and a greater reduction in bone turnover than did continued alendronate therapy [76].

\section{Recommendations \\ We recommend switching to teriparatide therapy the high-risk patients who are non-responders to BPs \\ We suggest switching to $\mathrm{SrR}$ or denosumab those patients that cannot carry on BPs treatment due to adverse effect of these drugs}

\section{Adherence}

In a cross-sectional, observational study in 2314 women with PMO, the rates of noncompliance to drug treatment were: alendronate $14.9 \%$, risedronate $11.4 \%$, raloxifene $11.3 \%$, HT $24.1 \%$, and tibolone $16.7 \%$ [147]. The rates of gastrointestinal side effects leading to noncompliance were similar for alendronate and risedronate (62.7 vs. $62.2 \%)$ [147]. 
Retrospective data showed that compliance with osteoporosis guidelines by physicians is not adequate [148]: among women diagnosed with PMO, only $13.2 \%$ had appropriate BMD follow-up, $42 \%$ were not on approved and guideline-endorsed pharmacotherapy for osteoporosis, and $26 \%$ had a fracture after diagnosis.

As adherence seems to be a problem in osteoporosis treatment both by the patient and the physician, the great variability in methods of studies that evaluate the impact of compliance to drug therapy on fracture risk makes it somewhat difficult to draw any definite conclusions on this issue [149].

\section{Recommendation}

We suggest considering low adherence as one of the possible causes of treatment failure, even though no definite conclusions on this issue can be drawn due to the lack of studies evaluating the impact of compliance to drug therapy on fracture risk

\section{Other forms of osteoporosis}

The present document focuses on forms representing a challenge for the endocrinologist. Glucocorticoid-induced osteoporosis (GIO) has not been addressed because many recent documents appeared on the topic.

\section{Male osteoporosis}

The incidence of vertebral and hip fractures is lower in men than in women. Anyway, it has been estimated that after 50 years one out of four men will suffer a fragility fracture [150]. Morbidity and mortality after hip fractures are higher in men than in women, particularly after the age of 70 [151].

Since male osteoporosis has a secondary etiology in many cases, before starting a drug treatment it is mandatory to differentiate the various forms of osteoporosis by means of an accurate clinical evaluation of the patient (table II in supplemental material) [11].

Currently the indications for drug therapy are not unequivocal. The use of algorithms that integrate risk factors with BMD may be useful in assessing fracture risk [20]. Pharmacological treatment must be carefully considered in men with a prior history of hip or vertebral fractures, particularly if they occurred after minor traumas or after the age of 50, or in those on long-term glucocorticoid therapy or having a FN BMD T-score $\leq-2.5$ [152].

At present many pharmacological treatments can be considered for osteoporosis in men: T, BPs (alendronate, risedronate, zoledronate), denosumab, and teriparatide.

\section{Testosterone}

$\mathrm{T}$ is the first-line treatment in men affected by primary or secondary hypogonadism [153]. Although the prevalence of hypogonadism in osteoporotic men has not been properly assessed, it is reasonable to measure serum $\mathrm{T}$ if concomitant symptoms or signs of androgen deficiency are present or suspected, subsequently considering for androgen treatment only patients with T levels $<200-300 \mathrm{ng} / \mathrm{dL}$ [154].

In men over 65 years $\mathrm{T}$ therapy was able to increase spine BMD by $3.4 \%$ when a threshold of $300 \mathrm{ng} / \mathrm{dL}$ was considered, while this rate grew up to $5.9 \%$ when plasma $\mathrm{T}$ threshold was set at $200 \mathrm{ng} / \mathrm{dL}$ [155]. No data are available on anti-fracture efficacy of $\mathrm{T}$ [156].

\section{Bisphosphonates}

A good quality trial has proven the efficacy of a 2-year daily oral alendronate therapy in increasing BMD. Although the study was not powered to assess anti-fracture efficacy, a not significant trend to reduction in the number of vertebral and non-vertebral fractures was observed in the treated group [157].

Similar data on BMD have been obtained with weekly oral risedronate, but even with this drug fracture incidence was not significantly different between risedronate and placebo-treated patients $[158,159]$.

In a 2-year multicenter, double blind RCT, once-yearly zoledronate (5 $\mathrm{mg} \mathrm{IV}$ ) increased BMD and decreased BTMs, comparably to $70 \mathrm{mg}$ weekly oral alendronate, with similar incidence of adverse events [160,161].

More recently in a multicenter, double-blind, placebocontrolled RCT zoledronate treatment was associated with a significantly reduced risk of vertebral fracture among men with primary or hypogonadism-associated osteoporosis. The treated group showed also higher BMD and lower BTMs [162].

The effects of BPs on BMD seem similar in men with normal serum $\mathrm{T}$ and in those with hypogonadism, but a recent paper on HIV-infected men, with osteoporosis or osteopenia, showed that risedronate increased BMD and reduced BTMs to a greater extent in patients with adequate androgenization compared to patients with symptomatic hypogonadism [163].

\section{Denosumab}

Denosumab is effective in reducing fracture incidence in men receiving ADT for non-metastatic prostate cancer (see below). Denosumab $60 \mathrm{mg}$ SC every 6 months resulted in BMD increase significantly higher than placebo $(+5.7 \%$ at the $\mathrm{LS},+2.4 \%$ at the $\mathrm{TH}$, and $+2.1 \%$ at the $\mathrm{FN}$ ) in a 
randomized, 1-year study in osteopenic men with or without fractures [164].

A 24-month extension of this study, the ADAMO trial, evaluated the efficacy and safety of denosumab for the treatment of men with low BMD. After the first year men from the original denosumab group continued to receive the drug for an additional year, while those coming from the placebo arm were assigned to the treatment with denosumab. This treatment for a second year maintains the ability to increase BMD, together with reductions in bone resorption. In men initiating denosumab during the second year BMD increased as well. The effects on BMD and BTMs were similar to those reported in women with PMO and in men with prostate cancer receiving ADT [165].

\section{Teriparatide}

Teriparatide is indicated to increase bone mass in men with primary or hypogonadal osteoporosis at high risk for fracture. A placebo-controlled, double-blind RCT with teriparatide was conducted on 437 men with low BMD and a $40 \%$ prevalence of fractures. Almost $50 \%$ of the enrolled patients had low serum T. BMD increase was significantly higher at all skeletal sites in the teriparatide arm of the study. Changes in BMD were similar to those described in women with PMO. Bone turnover increased significantly, with formation markers rising earlier than resorption ones. Treatment effects were independent on the presence of baseline low serum $\mathrm{T}$ [166].

Recommendations
We recommend, before starting a drug treatment, to
record a complete medical history and perform an
accurate clinical evaluation of the patient to
differentiate primary from secondary osteoporosis
We suggest $\mathrm{T}$ treatment in men with concomitant
symptoms of hypogonadism and $\mathrm{T}$ levels $<300 \mathrm{ng} / \mathrm{dL}$.
Treatment may be also considered in men without
symptoms, but with $\mathrm{T}$ levels $<200 \mathrm{ng} / \mathrm{dL}$
We suggest starting BPs, if T therapy does not increase
$\mathrm{BMD}$
We recommend the use of alendronate, risedronate or
denosumab in men with osteoporosis
We recommend the use of yearly IV zoledronate or daily
SC teriparatide in osteoporotic men at high risk of
fractures

Table 3 summarizes the efficacy of different drugs on fracture risk in males.
Table 3 Efficacy of different treatments on BMD and fracture risk in males (from 156, 157, 158, 159, 160, 162, 165, 167)

\begin{tabular}{lllll}
\hline Drug & BMD increase & Fractures & \\
\cline { 3 - 5 } & & Vertebral & Non-vertebral & Hip \\
\hline Testosterone & Yes & - & - & - \\
Alendronate & Yes & \pm & - & - \\
Risedronate & Yes & \pm & - & - \\
Zoledronate & Yes & + & - & - \\
Denosumab & Yes & \pm & - & - \\
Teriparatide & Yes & \pm & - & - \\
\hline
\end{tabular}

Beware that results are not to be regarded as comparative between different drugs, since they are not derived from head to head studies

- no available data or negative data, \pm fracture risk decrease obtained as secondary endpoint, + fracture risk decreased vs. placebo

\section{Androgen deprivation therapy}

ADT in men induces a severe sex-steroid deficiency resulting both in decreased BMD (at the hip and spine levels) and increased fracture incidence [167-173]. Radius BMD decline is faster than that at the spine and hip [174].

Men receiving ADT should receive drug therapy if they have a high risk of fracture as follows [151]:

- Low trauma hip or vertebral fractures;

- BMD T-score of the spine, FN and/or TH $\leq-2.5 \mathrm{SD}$;

- Long-term glucocorticoid therapy at pharmacological doses.

Other studies are needed to establish the correct therapeutic approach for men receiving ADT who have a T-score between -1.0 and -2.5 at the spine, $\mathrm{FN}$, or TH level, using national fracture risk assessment algorithms.

Physical exercise, calcium, vitamin D, BPs, denosumab, and SERMs have been proposed as treatment options for men on ADT.

\section{Physical exercise}

There are no conclusive data about the real effect of physical exercise on BMD and risk of fracture in men on ADT. A recent systematic review demonstrated that physical exercise may ameliorate many of the treatment-induced adverse effects of ADT, but its impact on bone health is still unclear [175]. Another cross-sectional study revealed a weak positive and significant association between endurance exercise and T-score of the hip. No significant correlation was found between physical exercise and LS T-score, even after adjusting for age, BMI and alcohol use [176]. 


\section{Calcium/vitamin D}

In men receiving ADT, calcium and vitamin D supplementation is controversial with inconsistent dosage recommendations. A critical review, analyzing the results of 12 clinical trials of calcium and vitamin D supplementation on BMD in men on ADT, showed the ineffectiveness of the commonly recommended doses, namely $0.5-1 \mathrm{~g}$ daily calcium plus $200-500$ IU daily vitamin D [177]. In a prospective longitudinal study, vitamin $\mathrm{D}$, but not calcium, seemed to increase LS BMD during the first year of ADT [178]. On the other hand, reduced daily calcium intake potentially represents an independent risk factor for osteoporosis in these patients [179].

\section{Bisphosphonates}

Treatment with BPs is able to prevent bone loss in men on ADT. However, most studies evaluated the ability of different BPs in preventing BMD decline, but they were not powered to evaluate fracture risk reduction [180-182].

Zoledronate was able to increase BMD in men with or without bone metastases treated with ADT [183, 184].

In a phase 3 double-blind placebo-controlled RCT on men treated with ADT, oral once-weekly $70 \mathrm{mg}$ alendronate increased both LS and TH BMD [185].

Oral risedronate significantly recovered BMD for up to 24 months compared with the control group after starting ADT [186].

In an open-label study, IV pamidronate prevented hip and LS bone loss in men treated with ADT [187].

Finally, also neridronate prevented ADT-induced bone loss in a small RCT in patients with prostate cancer [188].

\section{Denosumab}

Denosumab has been approved for prevention of treatmentrelated fragility fractures in men on ADT. In a double-blind multicenter placebo-controlled trial, denosumab $(60 \mathrm{mg} \mathrm{q}$ 6 months) determined a significant reduction of new vertebral fractures incidence at 36 months and an increase of BMD at all skeletal sites [174].

\section{SERMs}

SERMs are effective in ameliorating BMD and reducing fracture risk in men on ADT, but they are not approved for this use probably due to a poor risk/benefit ratio. Raloxifene treatment increased hip BMD in a 12-month open-label study in men on ADT [189]. In a phase 3 double-blind placebo-controlled trial, toremifene both improved BMD at all skeletal sites and reduced the incidence of new morphometric and clinical vertebral fractures, but it also increased the rate of venous thromboembolic events [190].

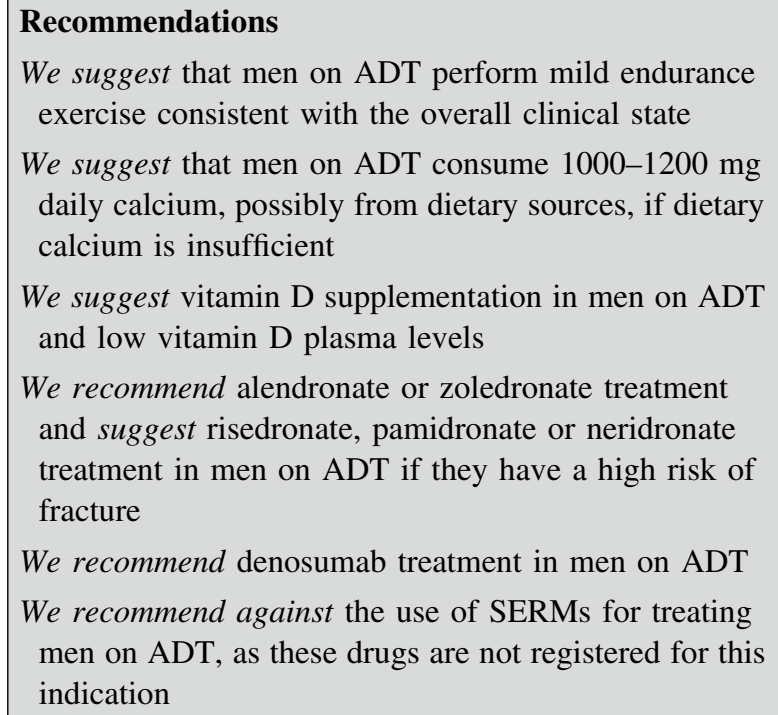

We recommend alendronate or zoledronate treatment and suggest risedronate, pamidronate or neridronate treatment in men on ADT if they have a high risk of fracture

We recommend denosumab treatment in men on ADT

We recommend against the use of SERMs for treating men on ADT, as these drugs are not registered for this indication

\section{Premenopausal osteoporosis}

Osteoporosis in premenopausal women is rare and it is usually due to other conditions or diseases or is of genetic origin (i.e. osteogenesis imperfecta, Marfan syndrome, Gaucher's disease) [191-193]. The pathophysiology of idiopathic osteoporosis is not well understood. Pregnancy-associated osteoporosis is a rare idiopathic form of spinal osteoporosis or transient osteoporosis of the hip. Preexisting low BMD and high bone turnover rate both during pregnancy and lactation may play an important pathophysiologic role [194].

Medical history, physical examination and laboratory tests should be performed to detect secondary causes of osteoporosis (table II in supplemental material). History of low trauma fractures is diagnostic for osteoporosis, but it is extremely rare in premenopausal females. The diagnosis of osteoporosis can be made even without fracture history, if a low BMD and a secondary cause of osteoporosis are both present.

The 2007 International Society for Clinical Densitometry Official Position recommends the use of BMD Z-score instead of T-score in premenopausal women. For $Z$-score values $<-2.0$ a definition of "BMD below the expected range for age" should be used [195]. However, low BMD alone does not represent a pathological state [196] and it is not sufficient to diagnose osteoporosis since relationships between BMD and fracture incidence have not been established in premenopausal women [197-199].

Finally, it should be reminded that fracture prediction tools such as the FRAX ${ }^{\circledR}$ are not applicable in subjects younger than 40 years. 
In case of secondary osteoporosis the first therapeutic approach should be addressed toward the removal or the management of the underlying cause (i.e. parathyroidectomy for primary hyperparathyroidism, gluten free diet for celiac disease, nutritional rehabilitation and weight gain for nervous anorexia).

When a "BMD below the expected range for age" is diagnosed, behavioral advices are mandatory. Weight-bearing exercise, adequate intake of calcium and vitamin D, smoking cessation and avoidance of excess alcohol are suggested, albeit no evidence is available on their real effect in reducing fracture rate [200].

BPs are the most studied drugs and they may be prescribed in the treatment of premenopausal osteoporosis, particularly in presence of fragility fractures. Anti-fracture efficacy of BPs has not been sufficiently documented in this setting, except for neridronate, pamidronate and risedronate in osteogenesis imperfecta [201-203]. More positive results have been obtained when BMD increase was considered as an endpoint of BP treatment in some conditions (i.e. inflammatory bowel diseases, nervous anorexia, cystic fibrosis, beta-thalassemia, osteogenesis imperfecta, Gaucher's disease), even though these studies have both small size and short duration (usually $<24$ months) [201-209].

The most frequent form of secondary osteoporosis that might require treatment in premenopausal women is GIO. Patients taking $7.5 \mathrm{mg}$ of daily glucocorticoids for more than 3 months with a prior history of fracture should be treated with BPs. Teriparatide should be used in patients with a higher risk of fracture or in those whose response to treatment is considered inadequate [210].

BPs administration during pregnancy could potentially lead to congenital malformations, [211-213]. Since BPs accumulate and remain for years in the skeleton, precaution is advised for their use before pregnancy and during lactation $[214,215]$.

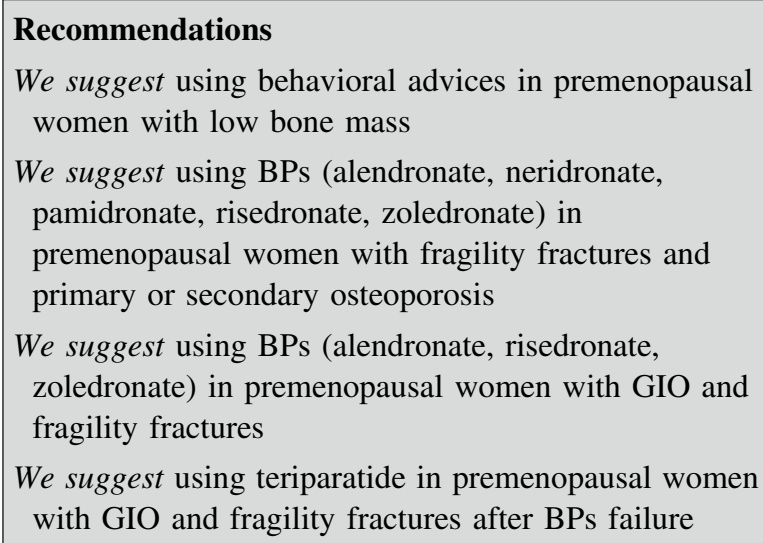

We suggest using teriparatide in premenopausal women with GIO and fragility fractures after BPs failure

\section{Aromatase inhibitors}

Premature ovarian suppression induced by GnRH agonists, chemotherapy, surgical removal, or irradiation is the first cause of bone damage in premenopausal women with $\mathrm{BC}$, with an estimated bone loss of about $8 \%$ within the first year [216]. In addition, both in pre- and postmenopausal women, AI can decrease BMD and increase fragility fracture incidence compared to tamoxifen [217-220]. In a study comparing anastrozole with tamoxifen the overall incidence of fractures was higher in the former group (11.0 vs. $7.7 \%$; OR 1.49; $95 \%$ CI 1.25-1.77) [221].

The extent of bone loss is different for the various molecules at LS or TH, reaching a 5-year reduction for anastrozole of -6.1 and $-7.2 \%$, respectively [218]. Letrozole and exemestane can induce a 2-year reduction in BMD by -5.3 and $-2.4 \%$ at LS, respectively, whereas the respective figures were -3.6 and $-1.8 \%$ at TH $[222,223]$. Over $30 \%$ of the patients starting on anastrozole will have a diagnosis of osteoporosis in the subsequent years [218].

Several RCTs indicate that both oral and IV BPs as well as denosumab have protecting effects on BMD in this setting. Zoledronate has shown a higher efficacy than oral BPs. In premenopausal women on anastrozole plus goserelin therapy the concomitant use of zoledronate (4 mg IV every 6 months) was able to improve BMD at 5 years, compared to the group treated only with tamoxifen plus goserelin [217].

The three "Zometa-Femara Adjuvant Synergy Trials" have compared the efficacy of zoledronate in postmenopausal women receiving adjuvant letrozole. The patients were randomly assigned to immediate zoledronate $(4 \mathrm{mg}$ IV q 6 months for 5 years), or zoledronate therapy starting after a decrease in BMD or a non-traumatic fracture. At 60 months patients in the immediate group showed a LS and TH BMD gain of +4.3 and $+1.6 \%$, respectively, while the respective figures in the delayed group were -5.4 and $-4.2 \%$. Also the patients with a normal baseline BMD (T-score $>-1$ ) showed a substantial decrease in LS $(-7.1 \%)$ if they were enrolled in the delayed group, while the immediate group achieved a $3.9 \%$ increase [224226]. Similar results were obtained in a fourth study, where patients had previously been treated with tamoxifen for 6 years and were then switched to letrozole [227].

Oral risedronate (35 mg weekly) given to postmenopausal BC women treated with anastrozole increased BMD at 24 months $(+2.2$ to $5.7 \%$ at $\mathrm{LS}$ and +1.6 to $1.8 \%$ at $\mathrm{TH})[228,229]$. In osteopenic postmenopausal women given anastrozole, patients treated with risedronate gained $+1.1 \%$ BMD at LS compared with a $2.6 \%$ decrease in those without BP [230]. 
In patients treated with anastrozole or letrozole, alendronate significantly increased LS BMD by $3 \%$ after a 6-month treatment [231]. Finally in the 24-month Arimidex-Ibandronate study, monthly $150 \mathrm{mg}$ oral ibandronate prevented bone loss in osteopenic women and in a small number of women with PMO [232].

Although all studies on BPs were not designed for fracture incidence, a recent meta-analysis found that zoledronate (4 mg q 6 months) reduced significantly the overall fracture rate (OR 0.78; $95 \%$ CI 0.63-0.96) [233].

Denosumab, $60 \mathrm{mg}$ q 6 months SC for 24 months in postmenopausal women with low bone mass, was associated with larger BMD gains than placebo across multiple skeletal sites regardless of patient subgroups (prior tamoxifen use, duration and type of AI, time since menopause) $[234,235]$. Denosumab reduced the risk of vertebral fractures after 36 months of treatment compared to placebo [236].

On the basis of the AI effects on bone loss and fracture risk, BMD should be measured before AI treatment or within 6 months from treatment start and known risk factors for fracture (table I in supplemental material) should be explored.

Treatment should be initiated in the presence of a fragility fracture irrespectively of BMD values, as well as in case of a baseline T-score $<-2.0 \mathrm{SD}$, or if the annual rate of bone loss results $>4 \%$ at LS or TH, or in women combining a T-score $<-1.0 \mathrm{SD}$ with more than one of the risk factors for fracture, and finally in women $>65$ years regardless of BMD [237-240].

In AI-treated patients the adverse event rates were similar to those described in the studies on primary osteoporosis, both for BPs and denosumab. The optimal duration of treatment has not been established but is reasonable to continue anti-resorptives until AI treatment is ongoing.

\footnotetext{
Recommendations

We suggest that measuring $\mathrm{BMD}$ before starting $\mathrm{AI}$ treatment is not strictly necessary

We recommend exploring known risk factors for fracture and correcting modifiable factors

We recommend using oral BPs (risedronate, ibandronate, alendronate) or IV zoledronate, or SC denosumab to prevent bone loss in women treated with $\mathrm{AI}$

We recommend using IV zoledronate or SC denosumab and suggest using oral BPs (risedronate, ibandronate, alendronate) to reduce fracture risk in women treated with AI

We recommend continuing anti-resorptive treatment possibly as long as AI therapy
}

\section{Conclusions}

Removal of modifiable risk factors as well as calcium and vitamin D levels optimization is a pre-requisite for any pharmacological strategy for osteoporosis treatment. An appropriate screening of secondary forms of osteoporosis is mandatory in the appropriate clinical setting. Start of treatments known to be detrimental to bone health, namely glucocorticoids, ADT and AI, should prompt a comprehensive treatment plan to preserve bone health or minimize the damage.

Several drugs are available for the treatment of PMO. Almost all demonstrated a high anti-fracture efficacy together with a good safety profile, leading to a positive risk/benefit balance. Whereas most have proven to significantly reduce the occurrence of vertebral fractures, some discrepancies remain regarding the level of evidence related to their non-vertebral or hip anti-fracture effect.

HT is no longer indicated for the management of PMO, but it might be considered for a limited length of time in the early postmenopausal woman with climacteric symptoms, with a careful individual evaluation of risk-benefit ratio.

SERMs might be a first-line option in early, asymptomatic, postmenopausal women, but could be also considered in women $<65$ years at high risk of vertebral fractures.

BP administration represents an effective choice in postmenopausal women $>65$ years at risk of vertebral fractures. Alendronate and risedronate could also be considered in women with established osteoporosis and high risk of hip fractures. Oral administration should be avoided in patients with delayed esophageal emptying and in those who are unable to maintain an upright position. These patients, and those with gastrointestinal adverse events, are candidates for IV zoledronate. Treatment can be continued for up to 5 years; the use for a longer period should be considered with caution. A drug holiday has been suggested because of the persistent anti-fracture efficacy of these drugs after withdrawal, but treatment can be continued in those with very high risk of fracture.

Denosumab might be the first choice in patients with renal failure and high risk of fractures, and after failure or adverse events of other treatments. Hypocalcemia must be corrected prior to denosumab administration, particularly in patients with severely impaired renal function. Patients should be monitored for the risk of infections.

Because of the intermittent administration, zoledronate (once a year) and denosumab (every 6 months) may be an attractive option for patients with low adherence to drugs.

The use of SrR should be restricted to patients with severe osteoporosis, who are intolerant to other treatments, provided that there is no history of prior or concomitant cerebral or cardiovascular diseases. 
Treatment with teriparatide should be reserved to established osteoporosis when prior therapies have failed and may be started soon after prior treatment withdrawal. Teriparatide should not be used in patients with hypercalcemia, neoplastic and metabolic bone diseases other than osteoporosis and should not be extended over 24 months. Antiresorptive therapy (BPs or denosumab) should be started upon termination of teriparatide to maintain its beneficial effects.

In conclusions, most women with PMO may need longterm treatment and the sequential use of different drugs.
An individualized approach should be defined when treatment is started taking into account the fracture risk, the efficacy, safety, convenience and life expectancy. Pharmacoeconomic issues and country-specific rules may influence the therapeutic strategy. The treating physician should choose the most suitable treatment for the individual patient based on medical history, fracture risk, drugs anti-fracture efficacy, presence of co-morbidities, previous treatment for osteoporosis, and preference of individual patients. Figure depicts a flowchart for the management of osteoporosis.

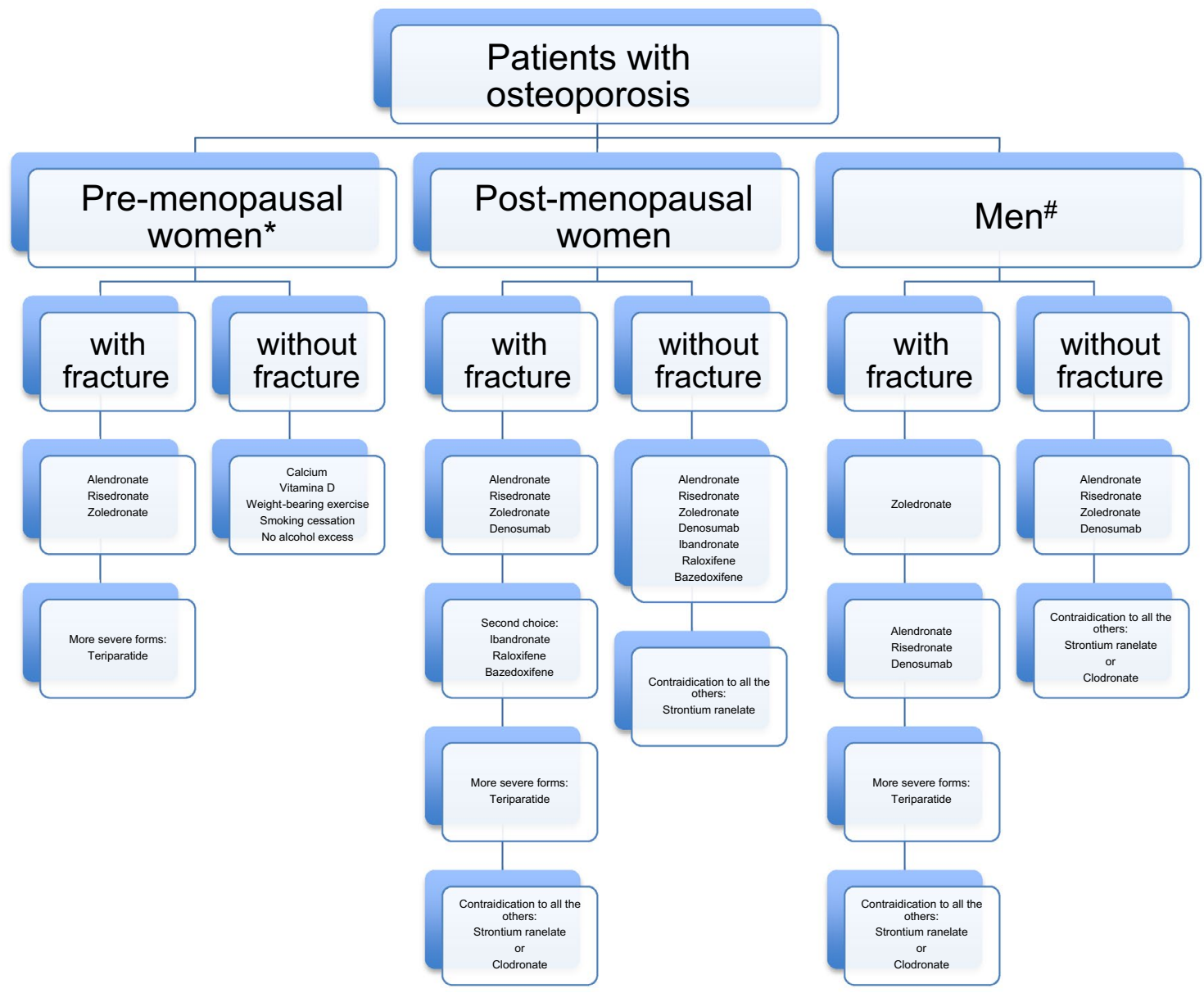

* No safety data for use in pregnancy. Always consider contraception. \# Always consider testosterone substitution in hypogonadal men. 
Acknowledgments We are indebted to Enrico Papini for revision and support.

\section{Compliance with ethical standards}

Conflicts of interest Fabio Vescini received Grants for scientific speeches by the following companies: Gilead Sciences, AbbVie, ViiV Healthcare, Bristol Myers Squibb, Abiogen Pharma, Merck Sharp \& Dhome, Amgen, Lilly pharmaceuticals, SPA pharma. Francisco Bandeira received research Grant (n 479948/2013-5) from Brasilian Council for Scientific Development and financial support for educational programs from Novartis. Laura Gianotti received financial support from MSD for attending meetings. Roberto Attanasio, Antonio Balestrieri, Stefania Bonadonna, Valentina Camozzi, Sara Cassibba, Roberto Cesareo, Iacopo Chiodini, Cristiano Maria Francucci, Franco Grimaldi, Rinaldo Guglielmi, Bruno Madeo, Claudio Marcocci, Andrea Palermo, Alfredo Scillitani, Edda Vignali, and Michele Zini declare that they have no conflict of interest.

Ethical approval This article does not contain any studies with human participants or animals performed by any of the authors.

Informed consent Does not apply to this kind of paper.

Open Access This article is distributed under the terms of the Creative Commons Attribution 4.0 International License (http://creativecommons.org/licenses/by/4.0/), which permits unrestricted use, distribution, and reproduction in any medium, provided you give appropriate credit to the original author(s) and the source, provide a link to the Creative Commons license, and indicate if changes were made.

\section{References}

1. Adami S, Giannini S, Bianchi G, Sinigaglia L, Di Munno O, Fiore CE, Minisola S, Rossini M (2009) Vitamin D status and response to treatment in post-menopausal osteoporosis. Osteoporos Int 20(2):239-244 (LoE $\otimes \otimes O O)$

2. GRADE Working Group website. http://www.gradeworkinggroup.org. (no LoE)

3. Atkins D, Best D, Briss PA, Eccles M, Falck-Ytter Y, Flottorp S, Guyatt GH, Harbour RT, Haugh MC, Henry D, Hill S, Jaeschke R, Leng G, Liberati A, Magrini N, Mason J, Middleton P, Mrukowicz J, O'Connell D, Oxman AD, Phillips B, Schünemann HJ, Edejer T, Varonen H, Vist GE, Williams JW Jr, Zaza S, GRADE Working Group (2004) Grading quality of evidence and strength of recommendations. Br Med J 328(7454):14901497 (no LoE)

4. Swiglo BA, Murad MH, Schünemann HJ, Kunz R, Vigersky RA, Guyatt GH, Montori VM (2008) A case for clarity, consistency, and helpfulness: state-of-the-art clinical practice guidelines in endocrinology using the Grading of Recommendations, Assessment, Development, and Evaluation System. J Clin Endocrinol Metab 93(3):666-673 (no LoE)

5. NIH Consensus Development Panel on Osteoporosis Prevention (2001) Diagnosis, and Therapy. Osteoporosis prevention, diagnosis, and therapy. JAMA 285(6):785-795 (no LoE)

6. Management of osteoporosis in postmenopausal women (2010) 2010 position statement of The North American Menopause Society. Menopause 17(1):25-54 (no LoE)

7. Miller PD, Siris ES, Barrett-Connor E, Faulkner KG, Wehren LE, Abbott TA, Chen YT, Berger ML, Santora AC, Sherwood LM (2002) Prediction of fracture risk in postmenopausal white women with peripheral bone densitometry: evidence from the National Osteoporosis Risk Assessment. J Bone Miner Res 17(12):2222-2230 (LoE $\otimes \otimes \otimes O)$

8. Rizzoli R, Bianchi ML, Garabédian M, McKay HA, Moreno LA (2010) Maximizing bone mineral mass gain during growth for the prevention of fractures in the adolescents and the elderly. Bone 46(2):294-305 (LoE $\otimes$ OOO)

9. Boota AM, de Ridderb MAJ, van der Sluisc IM, van Slobbed I, Krenninge EP, de Muinck Keizer-Schramad SMPF (2010) Peak bone mineral density, lean body mass and fractures. Bone 46(2):336-341 ( $\mathrm{LoE} \otimes \otimes \mathrm{OO})$

10. Melton LJ 3rd, Thamer M, Ray NF, Chan JK, Chesnut CH 3rd, Einhorn TA, Johnston CC, Raisz LG, Silverman SL, Siris ES (1997) Fractures attributable to osteoporosis: report from the National Osteoporosis Foundation. J Bone Miner Res 12(1):16 $23(\mathrm{LoE} \otimes \otimes 00)$

11. Khosla S, Amin S, Orwoll E (2008) Osteoporosis in men. Endocr Rev 29(4):441-464 (no LoE)

12. Rochira V, Balestrieri A, Madeo B, Zirilli L, Granata AR, Carani C (2006) Osteoporosis and male age-related hypogonadism, role of sex steroids on bone (patho)physiology. Eur $\mathrm{J}$ Endocrinol 154(2):175-185 (no LoE)

13. Evans RA, Marel GM, Lancaster EK, Kos S, Evans M, Wong SY (1988) Bone mass is low in relatives of osteoporotic patients. Ann Intern Med 109(11):870-873 (LoE @O०O)

14. Klotzbuecher CM, Ross PD, Landsman PB, Abbott TA 3rd, Berger M (2000) Patients with prior fractures have an increased risk of future fractures: a summary of the literature and statistical synthesis. J Bone Miner Res 15(4):721-739 (LoE $\otimes \otimes \otimes O)$

15. van der Voort DJ, Geusens PP, Dinant GJ (2001) Risk factors for osteoporosis related to their outcome: fractures. Osteoporos Int 12(8):630-638 (LoE $\otimes \otimes \otimes O)$

16. McCloskey E, Johansson H, Oden A, Kanis JA (2012) Fracture risk assessment. Clin Biochem 45(12):887-893 (no LoE)

17. Recker R, Lappe J, Davies K, Heaney R (2000) Characterization of perimenopausal bone loss: a prospective study. J Bone Miner Res 15(10):1965-1973 (LoE $\otimes \otimes O O)$

18. SIOMMMS (2014) Linee Guida per la diagnosi, prevenzione e terapia dell'osteoporosi. (no LoE)

19. Wainwright SA, Marshall LM, Ensrud KE, Cauley JA, Black DM, Hillier TA, Hochberg MC, Vogt MT, Orwoll ES; Study of Osteoporotic Fractures Research Group (2005) Hip fracture in women without osteoporosis. J Clin Endocrinol Metab 90(5):2787-2793 (LoE $\otimes \otimes \otimes O)$

20. Kanis JA, Johnell O, Oden A, Johansson H, McCloskey E (2008) FRAX and the assessment of fracture probability in men and women from the UK. Osteoporos Int 19(4):385-397 (LoE $\otimes \otimes \bigcirc 0)$

21. Silverman SL, Calderon AD (2010) The utility and limitations of FRAX: A US perspective. Curr Osteoporos Rep 8(4):192197 (no LoE)

22. Adami S, Bianchi G, Brandi ML, Di Munno O, Frediani B, Gatti D, Giannini S, Girasole G, Minisola G, Minisola S, Nuti R, Pedrazzoni M, Rossini M, Varenna M (2010) Validation and further development of the WHO 10-year fracture risk assessment tool in Italian postmenopausal women: project rationale and description. Clin Exp Rheumatol 28(4):561-570 (no LoE)

23. Kanis JA, McCloskey EV, Johansson H, Strom O, Borgstrom F, Oden A, National Osteoporosis Guideline Group (2008) Case finding for the management of osteoporosis with FRAX: assessment and intervention thresholds for the UK. Osteoporos Int 19(10):1395-1408 (LoE $\otimes \otimes O O)$

24. Hernlund $\mathrm{E}$, Svedbom A, Ivergård M, Compston J, Cooper C, Stenmark J, McCloskey EV, Jönsson B, Kanis JA (2013) Osteoporosis in the European Union: medical management, epidemiology and economic burden. A report prepared in collaboration 
with the International Osteoporosis Foundation (IOF) and the European Federation of Pharmaceutical Industry Associations (EFPIA). Arch Osteoporos 8(1-2):136 (LoE $\otimes \otimes \otimes O)$

25. Adami S, Bertoldo F, Gatti D, Minisola G, Rossini M, Sinigaglia L, Varenna M (2013) Treatment thresholds for osteoporosis and reimbursability criteria: perspectives associated with fracture risk-assessment tools. Calcif Tissue Int 93(3):195-200 (no LoE)

26. Dawson-Hughes B, Tosteson AN, Melton LJ 3rd, Baim S, Favus MJ, Khosla S, Lindsay RL, National Osteoporosis Foundation Guide Committee (2008) Implications of absolute fracture risk assessment for osteoporosis practice guidelines in the USA. Osteoporos Int 19(4):449-458 (LoE $\otimes \otimes O O)$

27. Watts NB, Bilezikian JP, Camacho PM, Greenspan SL, Harris ST, Hodgson SF, Kleerekoper M, Luckey MM, McClung MR, Pollack RP, Petak SM, AACE Osteoporosis Task Force (2010) American Association of Clinical Endocrinologists Medical Guidelines for Clinical Practice for the diagnosis and treatment of postmenopausal osteoporosis. Endocr Pract 16(Suppl 3):137 (no LoE)

28. Donaldson MG, Cawthon PM, Lui LY, Schousboe JT, Ensrud KE, Taylor BC, Cauley JA, Hillier TA, Dam TT, Curtis JR, Black DM, Bauer DC, Orwoll ES, Cummings SR, Osteoporotic Fractures in Men (MrOS) Study Group (2010) Estimates of the proportion of older white men who would be recommended for pharmacologic treatment by the new US National Osteoporosis Foundation guidelines. J Bone Miner Res 25(7):1506-1511 $(\mathrm{LoE} \otimes \otimes \otimes \mathrm{O})$

29. Fleisch H (1998) Bisphosphonates: mechanisms of action. Endocr Rev 19:80-100 (no LoE)

30. Russell RG, Watts NB, Ebetino FH, Rogers MJ (2008) Mechanisms of action of bisphosphonates: similarities and differences and their potential influence on clinical efficacy. Osteoporos Int 19:733-759 (no LoE)

31. Invernizzi M, Cisari C, Carda S (2015) The potential impact of new effervescent alendronate formulation on compliance and persistence in osteoporosis treatment. Aging Clin Exp Res 27(2):107-113 (no LoE)

32. Kanis JA, Reginster JY, Kaufman JM, Ringe JD, Adachi JD, Hiligsmann M, Rizzoli R, Cooper C (2012) A reappraisal of generic bisphosphonates in osteoporosis. Osteoporos Int 23(1):213-221 (no LoE)

33. Black DM, Bauer DC, Schwartz AV, Cummings SR, Rosen CJ (2012) Continuing bisphosphonate treatment for osteoporosisfor whom and for how long? N Engl J Med 366(22):2051-2053 (no LoE)

34. Food and Drug Administration. Background document for meeting of Advisory Committee for Reproductive Health Drugs and Drug Safety and Risk Management Advisory Committee. September 9, 2011. (no LoE)

35. Black DM, Cummings SR, Karpf DB, Cauley JA, Thompson DE, Nevitt MC, Bauer DC, Genant HK, Haskell WL, Marcus R, Ott SM, Torner JC, Quandt SA, Reiss TF, Ensrud KE (1996) Randomised trial of effect of alendronate on risk of fracture in women with existing vertebral fractures. Lancet 348(9041): 1535-1541 ( $\mathrm{LoE} \otimes \otimes \otimes \otimes)$

36. Black DM, Thompson ED, Bauer DC, Ensrud K, Musliner T, Hochberg MC, Nevitt MC, Suryawanshi S, Cummings SR, Fracture Intervention Trial (2000) Fracture risk reduction with alendronate in women with osteoporosis: the Fracture Intervention Trial. J Clin Endocrinol Metab 85(11):4118-4124 (LoE $\otimes \otimes \otimes \otimes)$

37. Black DM, Schwartz AV, Ensrud KE, Cauley JA, Levis S, Quandt SA, Satterfield S, Wallace RB, Bauer DC, Palermo L, Wehren LE, Lombardi A, Santora AC, Cummings SR, FLEX Research Group (2006) Effects of continuing or stopping alendronate after 5 years of treatment: the Fracture Intervention Trial Long-Term Extension (FLEX): a randomized trial. JAMA 296(24):2927-2938 (LoE $\otimes \otimes \otimes \otimes) ~$

38. Harris ST, Watts NB, Genant HK, McKeever CD, Hangartner T, Keller M, Chesnut CH 3rd, Brown J, Eriksen EF, Hoseyni MS, Axelrod DW, Miller PD (1999) Effects of risedronate treatment on vertebral and nonvertebral fractures in women with postmenopausal osteoporosis: a randomized controlled trial. JAMA 282(14):1344-1352 (LoE $\otimes \otimes \otimes \otimes)$

39. Reginster J, Minne HW, Sorensen OH, Hooper M, Roux C, Brandi ML, Lund B, Ethgen D, Pack S, Roumagnac I, Eastell R (2000) Randomized trial of the effects of risedronate on vertebral fractures in women with established postmenopausal osteoporosis. Vertebral Efficacy with Risedronate Therapy (VERT) Study Group. Osteoporos Int 11(1):83-91 (LoE $\otimes \otimes \otimes \otimes)$

40. Sorensen OH, Crawford GM, Mulder H, Hosking DJ, Gennari C, Mellstrom D, Pack S, Wenderoth D, Cooper C, Reginster JY (2003) Long-term efficacy of risedronate: a 5-year placebo-controlled clinical experience. Bone 32(2):120-126 (LoE $\otimes \otimes \otimes \otimes)$

41. Mellstrom DD, Sorensen OH, Goemaere S, Roux C, Johnson TD, Chines AA (2004) Seven years of treatment with risedronate in women with postmenopausal osteoporosis. Calcif Tissue Int 75(6):462-468 ( $\mathrm{LoE} \otimes \otimes \otimes O)$

42. Mortensen L, Charles P, Bekker PJ, Digennaro J, Johnston CC $\mathrm{Jr}$ (1998) Risedronate increases bone mass in an early postmenopausal population: 2 years of treatment plus 1 year of followup. J Clin Endocrinol Metab 83(2):396-402 (LoE $\otimes \otimes \otimes \otimes)$

43. McClung MR, Geusens P, Miller PD, Zippel H, Bensen WG, Roux C, Adami S, Fogelman I, Diamond T, Eastell R, Meunier PJ, Reginster JY, Hip Intervention Program Study Group (2001) Effect of risedronate on the risk of hip fracture in elderly women. Hip Intervention Program Study Group. N Engl J Med 344(5):333-340 (LoE $\otimes \otimes \otimes \otimes)$

44. Chesnut CH III, Skag A, Christiansen C, Recker R, Stakkestad JA, Hoiseth A, Felsenberg D, Huss H, Gilbride J, Schimmer RC, Delmas PD, Oral Ibandronate Osteoporosis Vertebral Fracture Trial in North America and Europe (BONE) (2004) Effects of oral ibandronate administered daily or intermittently on fracture risk in postmenopausal osteoporosis. J Bone Miner Res 19(8): 1241-1249 (LoE $\otimes \otimes \otimes \otimes)$

45. McClung MR, Wasnich RD, Recker R, Cauley JA, Chesnut CH 3rd, Ensrud KE, Burdeska A, Mills T; Oral Ibandronate Study Group (2004) Oral daily ibandronate prevents bone loss in early postmenopausal women without osteoporosis. J Bone Miner Res 19(1):11-18 (LoE $\otimes \otimes \otimes \otimes)$

46. Weiss HM, Pfaar U, Schweitzer A, Wiegand H, Skerjanec A, Schran H (2008) Biodistribution and plasma protein binding of zoledronic acid. Drug Metab Dispos 36(10):2043-2049 (no LoE)

47. Black DM, Delmas PD, Eastell R, Reid IR, Boonen S, Cauley JA, Cosman F, Lakatos P, Leung PC, Man Z, Mautalen C, Mesenbrink P, Hu H, Caminis J, Tong K, Rosario-Jansen T, Krasnow J, Hue TF, Sellmeyer D, Eriksen EF, Cummings SR, HORIZON Pivotal Fracture Trial (2007) Once-yearly zoledronic acid for treatment of postmenopausal osteoporosis. N Engl J Med 356(18):1809-1822 (LoE $\otimes \otimes \otimes \otimes) ~$

48. Eriksen EF, Lyles KW, Colón-Emeric CS, Pieper CF, Magaziner JS, Adachi JD, Hyldstrup L, Recknor C, Nordsletten L, Lavecchia C, Hu H, Boonen S, Mesenbrink P (2009) Antifracture efficacy and reduction of mortality in relation to timing of the first dose of zoledronic acid after hip fracture. J Bone Miner Res 24(7):1308-1313 (LoE $\otimes \otimes \otimes \otimes)$

49. Black DM, Reid IR, Boonen S, Bucci-Rechtweg C, Cauley JA, Cosman F, Cummings SR, Hue TF, Lippuner K, Lakatos P, Leung PC, Man Z, Martinez RL, Tan M, Ruzycky ME, Su G, Eastell R (2012) The effect of 3 versus 6 years of zoledronic 
acid treatment of osteoporosis: a randomized extension to the HORIZON-Pivotal Fracture Trial (PFT). J Bone Miner Res 27(2):243-254 (LoE $\otimes \otimes \otimes \otimes)$

50. Wark JD, Bensen W, Recknor C, Ryabitseva O, Chiodo J 3rd, Mesenbrink P, de Villiers TJ (2012) Treatment with acetaminophen/paracetamol or ibuprofen alleviates post-dose symptoms related to intravenous infusion with zoledronic acid $5 \mathrm{mg}$. Osteoporos Int 23(2):503-512 ( $\mathrm{LoE} \otimes \otimes \otimes \otimes)$

51. John Camm A (2010) Review of the cardiovascular safety of zoledronic acid and other bisphosphonates for the treatment of osteoporosis. Clin Ther 32(3):426-436 (no LoE)

52. Miller PD, Jamal SA, Evenepoel P, Eastell R, Boonen S (2013) Renal safety in patients treated with bisphosphonates for osteoporosis: a review. J Bone Miner Res 28(10):2049-2059 (no LoE)

53. Grbic JT, Black DM, Lyles KW, Reid DM, Orwoll E, McClung M, Bucci-Rechtweg C, Su G (2010) The incidence of osteonecrosis of the jaw in patients receiving 5 milligrams of zoledronic acid: data from the health outcomes and reduced incidence with zoledronic acid once yearly clinical trials program. $\mathbf{J}$ Am Dent Assoc 141(11):1365-1370 (LoE $\otimes \otimes \otimes O)$

54. Shane E, Burr D, Abrahamsen B, Adler RA, Brown TD, Cheung AM, Cosman F, Curtis JR, Dell R, Dempster DW, Ebeling PR, Einhorn TA, Genant HK, Geusens P, Klaushofer K, Lane JM, McKiernan F, McKinney R, Ng A, Nieves J, O'Keefe R, Papapoulos S, Howe TS, van der Meulen MC, Weinstein RS, Whyte MP (2014) Atypical subtrochanteric and diaphyseal femoral fractures: second report of a task force of the American Society for Bone and Mineral Research. J Bone Miner Res 29(1):1-23 $(\mathrm{LoE} \otimes \otimes \otimes O)$

55. Mc Closkey EV, Selby P, Robinson J, Francis RM, Kayan K, Beneton M, Jalava T, Pylkkanen L, Kenraali J, Aropuu S, Kanis JA (2004) Clodronate reduces vertebral fracture risk in women with postmenopausal or secondary osteoporosis: results of a double-blind placebo-controlled 3-year study. J Bone Miner Res 19(5):728-736 (LoE $\otimes \otimes \otimes \otimes)$

56. Mc Closkey EV, Beneton M, Charlesworth D, Kayan K, De Takats D, Dey A, Orgee J, Ashford R, Forster M, Cliffe J, Kersh L, Barzier J, Nichol J, Aropuu S, Jalava T, Kanis JA (2007) Clodronate reduces the incidences of fractures in communitydwelling elderly women unselected osteoporosis: results of a double blind, placebo controlled randomized study. J Bone Min Res 22(1): 135-141 ( $\mathrm{LoE} \otimes \otimes \otimes \otimes)$

57. Frediani B, Baraldi E, Cremonesi G (2014) Effect of clodronate treatment on risk of fracture: a systematic review and metaanalysis. Calcif Tissue Int 95(4):295-307 ( $\mathrm{LoE} \otimes \otimes \otimes \otimes)$

58. Saarto T, Vehmanen L, Blomqvist C, Eloma I (2008) Ten-year follow up of 3 years of oral adjuvant clodronate therapy shows significant prevention of osteoporosis on early stage breast can-

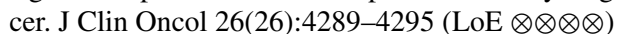

59. Frediani B, Falsetti B, Baldi F, Acciai C, Filippou G, Marcolongo R (2003) Effect of 4-year treatment with once weekly clodronate on prevention of corticosteroid induced bone loss and fractures in patients with arthritis: evaluation with dual energy X-ray absorptiometry and quantitative ultrasound. Bone 33(4):575-581 (LoE $\otimes \otimes \otimes \otimes)$

60. Frediani B (2011) Effects of two administration schemes of intramuscular clodronic acid on bone mineral a density, a randomized, open label parallel: group study. Clin Drug Invest 31(1):43-50 (LoE $\otimes \otimes \otimes \otimes)$

61. Aapro M, Abrahamsson PA, Body JJ, Coleman RE, Colomer R, Costa L, Crinò L, Dirix L, Gnant M, Gralow J, Hadji P, Hortobagyi GN, Jonat W, Lipton A, Monnier A, Paterson AHG, Rizzoli R, Saad F, Thurlimann B (2008) Guidance on the use of bisphosphonates in solid tumors: recommendations of an international expert panel. Ann Oncol 19(3):420-432 (no LoE)
62. Meunier PJ, Roux C, Seeman E, Ortolani S, Badurski JE, Spector TD, Cannata J, Balogh A, Lemmel EM, Pors-Nielsen S, Rizzoli R, Genant HK, Reginster JY (2004) The effects of strontium ranelate on the risk of vertebral fracture in women with postmenopausal osteoporosis. N Engl J Med 350(5):459-468 $(\mathrm{LoE} \otimes \otimes \otimes \otimes)$

63. Reginster JY, Seeman E, De Vernejoul MC, Adami S, Compston J, Phenekos C, Devogelaer JP, Curiel MD, Sawicki A, Goemaere S, Sorensen OH, Felsenberg D, Meunier PJ (2005) Strontium ranelate reduces the risk of nonvertebral fractures in postmenopausal women with osteoporosis: Treatment of Peripheral Osteoporosis (TROPOS) study. J Clin Endocrinol Metab 90(5):2816-2822 (LoE $\otimes \otimes \otimes \otimes)$

64. Reginster J, Kaufman J, Goemaere S, Devogelaer J, Benhamou C, Felsenberg D, Diaz-Curiel M, Brandi ML, Badurski J, Wark J, Balogh A, Bruyère O, Roux C (2012) Maintenance of antifracture efficacy over 10 years with strontium ranelate in postmenopausal osteoporosis. Osteoporos Int 23(3):1115-1122 $(\mathrm{LoE} \otimes \otimes \otimes 0)$

65. Varenna M, Bertoldo F, Di Monaco M, Giusti A, Martini G, Rossini M (2013) Safety profile of drugs used in the treatment of osteoporosis: a systematical review of the literature. Reumatismo 65(4):143-166 (no LoE)

66. European Medicines Agency (2013) PSUR assessment report for strontium ranelate. EMA/PRAC/136656/2013. (no LoE)

67. Cooper C, Fox KM, Borer JS (2014) Ischaemic cardiac events and use of strontium ranelate in postmenopausal osteoporosis: a nested case-control study in the CPRD. Osteoporos Int 25(2):737-745 ( $\mathrm{LoE} \otimes \otimes \otimes O)$

68. Abrahamsen B, Grove EL, Vestergaard P (2014) Nationwide registry based analysis of cardiovascular risk factors and adverse outcomes in patients treated with strontium ranelate. Osteoporos Int 25(2):757-762 ( $\mathrm{LoE} \otimes \otimes \otimes \mathrm{O})$

69. European Medicines Agency (2014) Protelos/Osseor to remain available but with further restrictions. EMA/235924/2014. (no LoE)

70. Diab DL, Watts NB (2014) Denosumab in osteoporosis. Expert Opin Drug Saf 13(2):247-253 (no LoE)

71. Cummings SR, San Martin J, McClung MR, Siris ES, Eastell R, Reid IR, Delmas P, Zoog HB, Austin M, Wang A, Kutilek S, Adami S, Zanchetta J, Libanati C, Siddhanti S, Christiansen C, FREEDOM Trial (2009) Denosumab for prevention of fractures in postmenopausal women with osteoporosis. N Engl J Med 361(8):756-765 ( $\mathrm{LoE} \otimes \otimes \otimes \otimes)$

72. Boonen S, Adachi JD, Man Z, Cummings SR, Lippuner K, Törring O, Gallagher JC, Farrerons J, Wang A, Franchimont N, San Martin J, Grauer A, McClung M (2011) Treatment with denosumab reduces the incidence of new vertebral and hip fractures in postmenopausal women at high risk. J Clin Endocrinol Metab 96(6): 1727-1736 (LoE $\otimes \otimes \otimes \otimes)$

73. McClung MR, Boonen S, Törring O, Roux C, Rizzoli R, Bone HG, Benhamou CL, Lems WF, Minisola S, Halse J, Hoeck HC, Eastell R, Wang A, Siddhanti S, Cummings SR (2012) Effect of denosumab treatment on the risk of fractures in subgroups of women with postmenopausal osteoporosis. J Bone Miner Res 27(1):211-218 (LoE $\otimes \otimes \otimes O)$

74. Papapoulos S, Chapurlat R, Libanati C, Brandi ML, Brown JP, Czerwiński E, Krieg MA, Man Z, Mellström D, Radominski SC, Reginster JY, Resch H, Román Ivorra JA, Roux C, Vittinghoff E, Austin M, Daizadeh N, Bradley MN, Grauer A, Cummings SR, Bone HG (2012) Five years of denosumab exposure in women with postmenopausal osteoporosis: results from the first 2 years of the FREEDOM extension. J Bone Miner Res 27(3):694-701 ( $\mathrm{LoE} \otimes \otimes \otimes \otimes)$

75. Brown JP, Prince RL, Deal C, Recker RR, Kiel DP, de Gregorio LH, Hadji P, Hofbauer LC, Alvaro-Gracia JM, Wang H, Austin 
M, Wagman RB, Newmark R, Libanati C, San Martin J, Bone HG (2009) Comparison of the effect of denosumab and alendronate on BMD and biochemical markers of bone turnover in postmenopausal women with low bone mass: a randomized, blinded, phase 3 trial. J Bone Miner Res 24(1):153-161 (LoE $\otimes \otimes \otimes \otimes)$

76. Kendler DL, Roux C, Benhamou CL, Brown JP, Lillestol M, Siddhanti S, Man HS, San Martin J, HG Bone (2010) Effects of denosumab on bone mineral density and bone turnover in postmenopausal women transitioning from alendronate therapy. J Bone Miner Res 25(1):72-81 ( $\mathrm{LoE} \otimes \otimes \otimes \otimes)$

77. Ishtiaq S, Fogelman I, Hampson G (2015) Treatment of postmenopausal osteoporosis: beyond bisphosphonates. J Endocrinol Invest 38(1):13-29 (no LoE)

78. Ettinger B, Black DM, Mitlak BH, Knickerbocker RK, Nickelsen T, Genant HK, Christiansen C, Delmas PD, Zanchetta JR, Stakkestad J, Glüer CC, Krueger K, Cohen FJ, Eckert S, Ensrud KE, Avioli LV, Lips P, Cummings SR, for the Multiple Outcomes of Raloxifene Evaluation (MORE) Investigators (1999) Reduction of vertebral fracture risk in postmenopausal women with osteoporosis treated with raloxifene: results from a 3-year randomized clinical trial. JAMA 282(7):637-645 (LoE $\otimes \otimes \otimes \otimes)$

79. Cummings SR, Ensrud K, Delmas PD, LaCroix AZ, Vukicevic S, Reid DM, Goldstein S, Sriram U, Lee A, Thompson J, Armstrong RA, Thompson DD, Powles T, Zanchetta J, Kendler D, Neven P, Eastell R, PEARL Study Investigators (2010) Lasofoxifene in postmenopausal women with osteoporosis. N Engl $\mathrm{J}$ Med 362(8):686-696 (LoE $\otimes \otimes \otimes \otimes)$

80. de Villiers TJ, Chines AA, Palacios S, Lips P, Sawicki AZ, Levine AB, Codreanu C, Kelepouris N, Brown JP (2011) Safety and tolerability of bazedoxifene in postmenopausal women with osteoporosis: results of a 5-year, randomized, placebocontrolled phase 3 trial. Osteoporos Int 22(2):567-576 (LoE $\otimes \otimes \otimes \otimes)$

81. Pinkerton JV, Goldstein SR (2010) Endometrial safety: a key hurdle for selective estrogen receptor modulators in development. Menopause 17(3):642-653 (no LoE)

82. Goldstein SR, Neven P, Cummings S, Colgan T, Runowicz CD, Krpan D, Proulx J, Johnson M, Thompson D, Thompson J, Sriram U (2011) Postmenopausal Evaluation and Risk Reduction With Lasofoxifene (PEARL) trial: 5-year gynecological outcomes. Menopause 18(1):17-22 ( $\operatorname{LoE} \otimes \otimes \otimes \otimes)$

83. Kanis JA, Johnell O, Black DM, Downs RW Jr, Sarkar S, Fuerst T, Secrest RJ, Pavo I (2003) Effect of raloxifene on the risk of new vertebral fracture in postmenopausal women with osteopenia or osteoporosis: a reanalysis of the Multiple Outcomes of Raloxifene Evaluation trial. Bone 33(3):293-300 ( $\mathrm{LoE} \otimes \otimes \otimes \otimes)$

84. Silverman SL, Christiansen C, Genant HK, Vukicevic S, Zanchetta JR, de Villiers TJ, Constantine GD, Chines AA (2008) Efficacy of bazedoxifene in reducing new vertebral fracture risk in postmenopausal women with osteoporosis: results from a 3-year, randomized, placebo-, and active-controlled clinical trial. J Bone Miner Res 23(12):1923-1934 (LoE $\otimes \otimes \otimes \otimes) ~$

85. Silverman SL, Chines AA, Kendler DL, Kung AW, Teglbjaerg CS, Felsenberg D, Mairon N, Constantine GD, Adachi JD, Bazedoxifene Study Group (2012) Sustained efficacy and safety of bazedoxifene in preventing fractures in postmenopausal women with osteoporosis: results of a 5-year, randomized, placebo-controlled study. Osteoporos Int 23(1):351-363 (LoE $\otimes \otimes \otimes \otimes)$

86. Lindsay R, Gallagher JC, Kagan R, Pickar JH, Constantine G (2009) Efficacy of tissue-selective estrogen complex of bazedoxifene/conjugated estrogens for osteoporosis prevention in at-risk postmenopausal women. Fertil Steril 92(3):1045-1052 $(\mathrm{LoE} \otimes \otimes \otimes \otimes)$
87. Writing Group for the PEPI (1996) Effects of hormone therapy on bone mineral density: results from the Postmenopausal Estrogen/Progestin Interventions (PEPI) trial. JAMA 276(17):1389-1396 (LoE $\otimes \otimes \otimes \otimes)$

88. Cauley JA, Robbins J, Chen Z, Cummings SR, Jackson RD, LaCroix AZ, LeBoff M, Lewis CE, McGowan J, Neuner J, Pettinger M, Stefanick ML, Wactawski-Wende J, Watts NB, Women's Health Initiative Investigators (2003) Effects of estrogen plus progestin on risk of fracture and bone mineral density: the Women's Health Initiative randomized trial. JAMA 290(13):1729-1738 (LoE $\otimes \otimes \otimes \otimes)$

89. Jackson RD, LaCroix AZ, Gass M, Wallace RB, Robbins J, Lewis CE, Bassford T, Beresford SA, Black HR, Blanchette P, Bonds DE, Brunner RL, Brzyski RG, Caan B, Cauley JA, Chlebowski RT, Cummings SR, Granek I, Hays J, Heiss G, Hendrix SL, Howard BV, Hsia J, Hubbell FA, Johnson KC, Judd H, Kotchen JM, Kuller LH, Langer RD, Lasser NL, Limacher MC, Ludlam S, Manson JE, Margolis KL, McGowan J, Ockene JK, O'Sullivan MJ, Phillips L, Prentice RL, Sarto GE, Stefanick ML, Van Horn L, Wactawski-Wende J, Whitlock E, Anderson GL, Assaf AR, Barad D, Women's Health Initiative Investigators (2006) Calcium plus vitamin D supplementation and the risk of fractures. N Engl J Med 354(7):669-683 (LoE $\otimes \otimes \otimes \otimes)$

90. Banks E, Beral V, Reeves G, Balkwill A, Barnes I, for the Million Women Study Collaborators (2004) Fracture incidence in relation to the pattern of use of hormone therapy in postmenopausal women. JAMA 291(18):2212-2220 (LoE $\otimes \otimes \otimes O)$

91. Heiss G, Wallace R, Anderson GL, Aragaki A, Beresford SA, Brzyski R, Chlebowski RT, Gass M, LaCroix A, Manson JE, Prentice RL, Rossouw J, Stefanick M, WHI Investigators (2008) Health risks and benefits 3 years after stopping randomized treatment with estrogen and progestin. JAMA 299(9):1036$1045(\mathrm{LoE} \otimes \otimes \otimes \otimes)$

92. LaCroix AZ, Chlebowski RT, Manson JE, Aragaki AK, Johnson KC, Martin L, Margolis KL, Stefanick ML, Brzyski R, Curb JD, Howard BV, Lewis CE, Wactawski-Wende J, WHI Investigators (2011) Health outcomes after stopping conjugated equine estrogens among postmenopausal women with prior hysterectomy: a randomized controlled trial. JAMA 305(13):1305-1314 $(\operatorname{LoE} \otimes \otimes \otimes \otimes)$

93. Chlebowski RT, Hendrix SL, Langer RD, Stefanick ML, Gass M, Lane D, Rodabough RJ, Gilligan MA, Cyr MG, Thomson CA, Khandekar J, Petrovitch H, McTiernan A, WHI Investigators (2003) Influence of estrogen plus progestin on breast cancer and mammography in healthy postmenopausal women: the Women's Health Initiative Randomized Trial. JAMA 289(24):3243-3253 (LoE $\otimes \otimes \otimes \otimes) ~$

94. Wassertheil-Smoller S, Hendrix SL, Limacher M, Heiss G, Kooperberg C, Baird A, Kotchen T, Curb JD, Black H, Rossouw JE, Aragaki A, Safford M, Stein E, Laowattana S, Mysiw WJ, WHI Investigators (2003) Effect of estrogen plus progestin on stroke in postmenopausal women: the Women's Health Initiative: a randomized trial. JAMA 289(20):2673-2684 (LoE $\otimes \otimes \otimes \otimes)$

95. Manson JE, Hsia J, Johnson KC, Rossouw JE, Assaf AR, Lasser NL, Trevisan M, Black HR, Heckbert SR, Detrano R, Strickland OL, Wong ND, Crouse JR, Stein E, Cushman M, Women's Health Initiative Investigators (2003) Estrogen plus progestin and the risk of coronary heart disease. $\mathrm{N}$ Engl J Med 349(6):523-534 ( $\mathrm{LoE} \otimes \otimes \otimes \otimes)$

96. Anderson GL, Limacher M, Assaf AR, Bassford T, Beresford SA, Black H, Bonds D, Brunner R, Brzyski R, Caan B, Chlebowski R, Curb D, Gass M, Hays J, Heiss G, Hendrix S, Howard BV, Hsia J, Hubbell A, Jackson R, Johnson KC, Judd H, Kotchen JM, Kuller L, LaCroix AZ, Lane D, Langer RD, Lasser N, Lewis CE, Manson J, Margolis K, Ockene J, O'Sullivan MJ, 
Phillips L, Prentice RL, Ritenbaugh C, Robbins J, Rossouw JE, Sarto G, Stefanick ML, Van Horn L, Wactawski-Wende J, Wallace R, Wassertheil-Smoller S, Women's Health Initiative Steering Committee (2004) Effects of conjugated equine estrogen in postmenopausal women with hysterectomy: the Women's Health Initiative randomized controlled trial. JAMA 291(14):1701-1712 ( $\mathrm{LoE} \otimes \otimes \otimes \otimes)$

97. Silva BC, Costa AG, Cusano NE, Kousteni S, Bilezikian JP (2011) Catabolic and anabolic actions of parathyroid hormone on the skeleton. J Endocrinol Invest 34(10):801-810 (no LoE)

98. Saag KG, Zanchetta JR, Devogelaer JP, Adler RA, Eastell R, See K, Krege JH, Krohn K, Warner MR (2009) Effects of teriparatide versus alendronate for treating glucocorticoid-induced osteoporosis: 36-month results of a randomized, double-blind, controlled trial. Arthritis Rheum 60(11):3346-3355 (LoE $\otimes \otimes \otimes \otimes)$

99. Vahle JL, Sato M, Long GG, Young JK, Francis PC, Engelhardt JA, Westmore MS, Linda Y, Nold JB (2002) Skeletal changes in rats given daily subcutaneous injections of recombinant human parathyroid hormone (1-34) for 2 years and relevance to human safety. Toxicol Pathol 30(3):312-321 (no LoE)

100. Neer RM, Arnaud CD, Zanchetta JR, Prince R, Gaich GA, Reginster JY, Hodsman AB, Eriksen EF, Ish-Shalom S, Genant HK, Wang O, Mitlak BH (2001) Effect of parathyroid hormone (1-34) on fractures and bone mineral density in postmenopausal women with osteoporosis. N Engl J Med 344(19):1434$1441(\mathrm{LoE} \otimes \otimes \otimes \otimes)$

101. Lindsay R, Scheele WH, Neer R, Pohl G, Adami S, Mautalen C, Reginster JY, Stepan JJ, Myers SL, Mitlak BH (2004) Sustained vertebral fracture risk reduction after withdrawal of teriparatide in postmenopausal women with osteoporosis. Arch Intern Med 164(18):2024-2030 (LoE $\otimes \otimes \otimes \otimes)$

102. Prince R, Sipos A, Hossain A, Syversen U, Ish-Shalom S, Marcinowska E, Halse J, Lindsay R, Dalsky GP, Mitlak BH (2005) Sustained nonvertebral fragility fracture risk reduction after discontinuation of teriparatide treatment. J Bone Miner Res 20(9):1507-1513 (LoE $\otimes \otimes \otimes O)$

103. Cosman F, Nieves J, Woelfert L, Formica C, Gordon S, Shen V, Lindsay R (2001) Parathyroid hormone added to established hormone therapy: effects on vertebral fracture and maintenance of bone mass after parathyroid hormone withdrawal. J Bone Miner Res 16(5):925-931 (LoE $\otimes \otimes \otimes \otimes) ~$

104. Ettinger B, San Martin J, Crans G, Pavo I (2004) Differential effects of teriparatide on BMD after treatment with raloxifene or alendronate. J Bone Miner Res 19(5):745-751 (LoE $\otimes \otimes \bigcirc 0)$

105. Cosman F, Wermers RA, Recknor C, Mauck KF, Xie L, Glass EV, Krege JH (2009) Effects of teriparatide in postmenopausal women with osteoporosis on prior alendronate or raloxifene: differences between stopping and continuing the antiresorptive agent. J Clin Endocrinol Metab 94(10):3772-3780 (LoE $\otimes \otimes \otimes \otimes)$

106. Miller PD, Delmas PD, Lindsay R, Watts NB, Luckey M, Adachi J, Saag K, Greenspan SL, Seeman E, Boonen S, Meeves S, Lang TF, Bilezikian JP, (2008) Open-label Study to Determine How Prior Therapy with Alendronate or Risedronate in Postmenopausal Women with Osteoporosis Influences the Clinical Effectiveness of Teriparatide Investigators. Early responsiveness of women with osteoporosis to teriparatide after therapy with alendronate or risedronate. J Clin Endocrinol Metab 93(10):3785-3793 ( $\mathrm{LoE} \otimes \otimes O O)$

107. Obermayer-Pietsch BM, Marin F, McCloskey EV, Hadji P, Farrerons J, Boonen S, Audran M, Barker C, Anastasilakis AD, Fraser WD, Nickelsen T, EUROFORS Investigators (2008) Effects of 2 years of daily teriparatide treatment on BMD in postmenopausal women with severe osteoporosis with and without prior antiresorptive treatment. J Bone Miner Res 23(10): 1591-1600 (LoE $\otimes \otimes \bigcirc O)$

108. Boonen S, Marin F, Obermayer-Pietsch B, Simoes ME, Barker C, Glass EV, Hadji P, Lyritis G, Oertel H, Nickelsen T, McCloskey EV, EUROFORS Investigators (2008) Effects of previous antiresorptive therapy on the bone mineral density response to 2 years of teriparatide treatment in postmenopausal women with osteoporosis. J Clin Endocrinol Metab 93(3):852-860 $(\mathrm{LoE} \otimes \otimes \mathrm{OO})$

109. Cosman F, Nieves J, Zion M, Woelfert L, Luckey M, Lindsay R (2005) Daily and cyclic parathyroid hormone in women receiving alendronate. N Engl J Med 353(6):566-575 (LoE $\otimes \otimes \otimes \otimes) ~$

110. Vasikaran S, Eastell R, Bruyère $\mathrm{O}$, Foldes AJ, Garnero $\mathrm{P}$, Griesmacher A, McClung M, Morris HA, Silverman S, Trenti T, Wahl DA, Cooper C, Kanis JA, IOF-IFCC Bone Marker Standards Working Group (2011) Markers of bone turnover for the prediction of fracture risk and monitoring of osteoporosis treatment: a need for international reference standards. Osteoporos Int 22(2):391-420 ( $\mathrm{LoE} \otimes \otimes \otimes O)$

111. Burch J, Rice S, Yang H, Neilson A, Stirk L, Francis R, Holloway P, Selby P, Craig D (2014) Systematic review of the use of bone turnover markers for monitoring the response to osteoporosis treatment: the secondary prevention of fractures, and primary prevention of fractures in high-risk groups. Health Technol Assess 18(11):1-180 ( $\mathrm{LoE} \otimes \otimes \otimes O)$

112. Cummings SR, Karpf DB, Harris F, Genant HK, Ensrud K, LaCroix AZ, Black DM (2002) Improvement in spine bone density and reduction in risk of vertebral fractures during treatment with antiresorptive drugs. Am J Med 112(4):281-289 (LoE $\otimes \otimes \otimes \otimes)$

113. Watts NB, Cooper C, Lindsay R, Eastell R, Manhart MD, Barton IP, van Staa TP, Adachi JD (2004) Relationship between changes in bone mineral density and vertebral fracture risk associated with risedronate: greater increases in bone mineral density do not relate to greater decreases in fracture risk. J Clin Densitom 7(3):255-261 (LoE $\otimes \otimes \otimes \otimes)$

114. Bauer DC, Black DM, Garnero P, Hochberg M, Ott S, Orloff J, Thompson DE, Ewing SK, Delmas PD (2004) Change in bone turnover and hip, non-spine, and vertebral fracture in alendronate-treated women: the fracture intervention trial. J Bone Miner Res 19(8):1250-1258 (LoE $\otimes \otimes \otimes \otimes)$

115. Eastell R, Barton I, Hannon RA, Chines A, Garnero P, Delmas PD (2003) Relationship of early changes in bone resorption to the reduction in fracture risk with risedronate. J Bone Miner Res 18(6):1051-1056 (LoE $\otimes \otimes O \bigcirc)$

116. Delmas PD, Munoz F, Black DM, Cosman F, Boonen S, Watts NB, Kendler D, Eriksen EF, Mesenbrink PG, Eastell R, The HORIZON-PFT Research Group (2009) Effects of yearly zoledronic acid $5 \mathrm{mg}$ on bone turnover markers and relation of PINP with fracture reduction in postmenopausal women with osteoporosis. J Bone Miner Res 24(9):1544-1551 (LoE $\otimes \otimes \otimes \otimes)$

117. Chen P, Satterwhite JH, Licata AA, Lewiecki EM, Sipos AA, Misurski DM, Wagman RB (2005) Early changes in biochemical markers of bone formation predict BMD response to teriparatide in postmenopausal women with osteoporosis. J Bone Miner Res 20(6):962-970 ( $\mathrm{LoE} \otimes \otimes \otimes \otimes)$

118. Hlaing TT, Compston JE (2014) Biochemical markers of bone turn over uses and limitations. Ann Clin Biochem 51(2):189202 (no LoE)

119. Lotz JC, Cheal EJ, Hayes WC (1991) Fracture prediction for the proximal femur using finite element models: Part I-Linear analysis. J Biomech Eng 113(4):353-360 (no LoE)

120. Hochberg MC, Greenspan S, Wasnich RD, Miller P, Thompson DE, Ross PD (2002) Changes in bone density and turnover explain the reductions in incidence of nonvertebral fractures that occur during treatment with antiresorptive agents. J Clin Endocrinol Metab 87(4):1586-1592 (LoE $\otimes \otimes \otimes \otimes) ~$ 
121. Watts NB, Geusens P, Barton IP, Felsenberg D (2005) Relationship between changes in BMD and nonvertebral fracture incidence associated with risedronate: reduction in risk of nonvertebral fracture is not related to change in BMD. J Bone Miner Res 20(12):2097-2104 (LoE $\otimes \otimes \otimes O)$

122. Sarkar S, Mitlak BH, Wong M, Stock JL, Black DM, Harper KD (2002) Relationships between bone mineral density and incident vertebral fracture risk with raloxifene therapy. J Bone Miner Res 17(1):1-10 ( $\mathrm{LoE} \otimes \otimes \otimes \otimes)$

123. Chen P, Miller PD, Delmas PD, Misurski DA, Krege JH (2006) Change in lumbar spine BMD and vertebral fracture risk reduction in teriparatide-treated postmenopausal women with osteoporosis. J Bone Miner Res 21(11):1785-1790 (LoE $\otimes \otimes \otimes \otimes)$

124. Austin M, Yang YC, Vittinghoff E, Adami S, Boonen S, Bauer DC, Bianchi G, Bolognese MA, Christiansen C, Eastell R, Grauer A, Hawkins F, Kendler DL, Oliveri B, McClung MR, Reid IR, Siris ES, Zanchetta J, Zerbini CA, Libanati C, Cummings SR, FREEDOM Trial (2012) Relationship between bone mineral density changes with denosumab treatment and risk reduction for vertebral and nonvertebral fractures. J Bone Miner Res 27(3):687-693 (LoE $\otimes \otimes \otimes \otimes)$

125. Bruyere O, Roux C, Detilleux J, Slosman DO, Spector TD, Fardellone P, Brixen K, Devogelaer JP, Diaz-Curiel M, Albanese C, Kaufman JM, Pors-Nielsen S, Reginster JY (2007) Relationship between bone mineral density changes and fracture risk reduction in patients treated with strontium ranelate. $\mathrm{J}$ Clin Endocrinol Metab 92(8):3076-3081 (LoE $\otimes \otimes \otimes \otimes) ~$

126. Baim S, Binkley N, Bilezikian JP, Kendler DL, Hans DB, Lewiecki EM, Silverman S (2008) Official Positions of the International Society for Clinical Densitometry and executive summary of the 2007 ISCD Position Development Conference. J Clin Densitom 11(1):75-91 (no LoE)

127. Delmas PD, Li Z, Cooper C (2004) Relationship between changes in bone mineral density and fracture risk reduction with antiresorptive drugs: some issues with meta-analyses. J Bone Miner Res 19(2):330-337 (no LoE)

128. McCloskey E, Leslie E (2013) Goal-directed therapy in osteoporosis. J Bone Miner Res 28(3):439-441 (no LoE)

129. Bandeira F, De Paula F, Lazaretti-Castro M, Premaor M (2014) Targets in osteoporosis treatment. Arq Bras Endocrinol Metab 58(5):409-410 (no LoE)

130. Johnell O, Oden A, Caulin F, Kanis JA (2001) Acute and long term increase in fracture risk after hospitalization for vertebral fracture. Osteoporos Int 12(3):207-214 (LoE $\otimes \otimes \otimes O)$

131. Johnell O, Kanis JA, Oden A, Sernbo I, Redlund-Johnell I, Pettersen C, De Laet C, Jonsson B (2004) Fracture risk following an osteoporotic fracture. Osteoporos Int 15(3):175-179 (LoE $\otimes \otimes \otimes 0)$

132. Bauer DC, Garnero P, Hochberg MC, Santora A, Delmas P, Ewing SK, Black DM; Fracture Intervention Research Group (2006) Pretreatment levels of bone turnover and the antifracture efficacy of alendronate: the Fracture Intervention Trial. J Bone Miner Res 21(2):292-299 (LoE $\otimes \otimes \otimes \otimes)$

133. Sebba AI (2008) Significance of a decline in bone mineral density while receiving oral bisphosphonate treatment. Clin Ther 30(3):443-452 (LoE $\otimes \otimes O O)$

134. Santos LL, Cavalcanti TB, Bandeira FA (2012) Vascular effects of bisphosphonates-a systematic review. Clin Med Insights Endocrinol Diabetes 5:47-54 (LoE $\otimes \otimes O O)$

135. Carvalho NN, Voss LA, Almeida MO, Salgado CL, Bandeira F (2011) Atypical femoral fractures during prolonged use of bisphosphonates: short-term responses to strontium ranelate and teriparatide. J Clin Endocrinol Metab 96(9):2675-2680 (LoE $\otimes 000)$

136. Park-Wyllie LY, Mamdani MM, Juurlink DN, Hawker GA, Gunraj N, Austin PC, Whelan DB, Weiler PJ, Laupacis A
(2011) Bisphosphonate use and the risk of subtrochanteric or femoral shaft fractures in older women. JAMA 305(8):783-789 $(\mathrm{LoE} \otimes \otimes \otimes \mathrm{O})$

137. Aspenberg P (2014) Denosumab and atypical femoral fractures. Acta Orthop 85(1): 1 (no LoE)

138. Whitaker M, Guo J, Kehoe T, Benson J (2012) Bisphosphonates for Osteoporosis-Where do we go from here? New Engl J Med 366(22):2048-2051 (no LoE)

139. Sousa IL, Diniz ET, Marques TF, Bandeira F (2010) Short-term bone marker responses to teriparatide and strontium ranelate in patients with osteoporosis previously treated with bisphosphonates. Arq Bras Endocrinol Metab 54(2):244-249 (LoE $\otimes 000)$

140. Lima H, Maia J, Bandeira F (2014) Trajectories of bone remodeling markers and bone mineral density during treatment with strontium ranelate in postmenopausal women previously treated with bisphosphonates. Clin Med Insights Endocrinol Diabetes 7:7-11 (LoE $\otimes 000)$

141. Middleton ET, Steel SA, Aye M, Doherty SM (2012) The effect of prior bisphosphonate therapy on the subsequent therapeutic effects of strontium ranelate over 2 years. Osteoporos Int 23(1):295-303 ( $\mathrm{LoE} \otimes \otimes 00)$

142. Jakob F, Oertel H, Langdahl B, Ljunggren O, Barrett A, Karras D, Walsh JB, Fahrleitner-Pammer A, Rajzbaum G, Barker C, Lems WF, Marin F (2012) Effects of teriparatide in postmenopausal women with osteoporosis pre-treated with bisphosphonates: 36-month results from the European Forsteo Observational Study. Eur J Endocrinol 166(1):87-97 (LoE $\otimes \otimes \otimes O)$

143. Black DM, Bilezikian JP, Ensrud KE, Greenspan SL, Palermo L, Hue T, Lang TF, McGowan JA, Rosen CJ; PaTH Study Investigators (2005) One year of alendronate after 1 year of parathyroid hormone (1-84) for osteoporosis. N Engl J Med 353(6):555-565 (LoE $\otimes \otimes \otimes \otimes)$

144. Rhee Y, Won YY, Baek MH, Lim SK (2004) Maintenance of increased bone mass after recombinant human parathyroid hormone (1-84) with sequential zoledronate treatment in ovariectomized rats. J Bone Miner Res 19(6):931-937 (LoE $\otimes \otimes O O)$

145. Leder BZ, Tsai JN, Uihlein AV, Wallace PM, Lee H, Neer RM, Burnett-Bowie SA (2015) Denosumab and teriparatide transitions in postmenopausal osteoporosis (the DATA-Switch study): extension of a randomised controlled trial. Lancet 386(9999):1147-1155 ( $\mathrm{LoE} \otimes \otimes \otimes \otimes)$

146. Eastell R, Nickelsen T, Marin F, Barker C, Hadji P, Farrerons J, Audran M, Boonen S, Brixen K, Gomes JM, ObermayerPietsch B, Avramidis A, Sigurdsson G, Glüer CC (2009) Sequential treatment of severe postmenopausal osteoporosis after teriparatide: final results of the randomized, controlled European Study of Forsteo (EUROFORS). J Bone Miner Res 24(4):726-736 ( $\mathrm{LoE} \otimes \otimes \otimes \otimes)$

147. Jakob F, Marin F, Martín-Mola E, Torgerson D, Fardellone P, Adami S, Thalassinos NC, Sykes D, Melo-Gomes J, Chinn C, Nicholson T, Cooper C (2006) Characterization of patients with an inadequate clinical outcome from osteoporosis therapy: the Observational Study of Severe Osteoporosis (OSSO). Q J Med 99(8):531-543 (LoE $\otimes \otimes \otimes O)$

148. Mountjoy CR, Shrader SP, Ragucci KR (2009) Compliance with osteoporosis treatment guidelines in postmenopausal women. Ann Pharmacother 43(2):242-250 (LoE $\otimes \otimes O O)$

149. Nikitovic M, Solomon DH, Cadarette SM (2010) Methods to examine the impact of compliance to osteoporosis pharmacotherapy on fracture risk: systematic review and recommendations. Ther Adv Chronic Dis 1(4):149-162 (LoE $\otimes \otimes \otimes O)$

150. National Osteoporosis Foundation. Just for men. http://nof.org/ articles/236. (no LoE)

151. Watts NB, Adler RA, Bilezikian JP, Drake MT, Eastell R, Orwoll ES, Filkenstein JS (2012) Osteoporosis in men: an 
Endocrine Society clinical practice guideline. J Clin Endocrinol Metab 97(6):1802-1822 (no LoE)

152. Ensrud KE, Taylor BC, Peters KW, Gourlay ML, Donaldson MG, Leslie WD, Blackwell TL, Fink HA, Orwoll ES, Schousboe J, Osteoporotic Fractures in Men Study Group (2014) Implications of expanding indications for drug treatment to prevent fracture in older men in United States: cross sectional and longitudinal analysis of prospective cohort study. BMJ 349:g4120 (LoE $\otimes \otimes \otimes O)$

153. Finkelstein JS, Klibanski A, Neer RM, Doppelt SH, Rosenthal DI, Segre GV, Crowley WF Jr (1989) Increases in bone density during treatment of men with idiopathic hypogonadotropic hypogonadism. J Clin Endocrinol Metab 69(4):776-783 (LoE $\otimes \otimes 00)$

154. Buvat J, Maggi M, Guay A, Torres LO (2013) Testosterone deficiency in men: systematic review and standard operating procedures for diagnosis and treatment. J Sex Med 10(1):245-284 $(\mathrm{LoE} \otimes \otimes O O)$

155. Snyder PJ, Peachey H, Hannoush P, Berlin JA, Loh L, Holmes JH, Dlewati A, Staley J, Santanna J, Kapoor SC, Attie MF, Haddad JG Jr, Strom BL (1999) Effect of testosterone treatment on bone mineral density in men over 65 years of age. J Clin Endocrinol Metab 84(6):1966-1972 (LoE $\otimes \otimes \otimes \otimes)$

156. Isidori AM, Balercia G, Calogero AE, Corona G, Ferlin A, Francavilla S, Santi D, Maggi M (2015) Outcomes of androgen replacement therapy in adult male hypogonadism: recommendations from the Italian Society of Endocrinology. J Endocrinol Invest 38(1):103-112 (no LoE)

157. Orwoll E, Ettinger M, Weiss S, Miller P, Kendler D, Graham J, Adami S, Weber K, Lorenc R, Pietschmann P, Vandormael K, Lombardi A (2000) Alendronate for the treatment of osteoporosis in men. N Engl J Med 343(9):604-610 (LoE $\otimes \otimes \otimes \otimes)$

158. Ringe JD, Faber H, Farahmand P, Dorst A (2006) Efficacy of risedronate in men with primary and secondary osteoporosis: results of a 1-year study. Rheumatol Int 26(5):427-431 (LoE $\otimes \otimes \otimes 0)$

159. Boonen S, Orwoll ES, Wenderoth D, Stoner KJ, Eusebio R, Delmas PD (2009) Once-weekly risedronate in men with osteoporosis: results of a 2-year, placebo-controlled, double-blind, multicenter study. J Bone Miner Res 24(4):719-725 (LoE $\otimes \otimes \otimes \otimes)$

160. Orwoll ES, Miller PD, Adachi JD, Brown J, Adler RA, Kendler D, Bucci-Rechtweg C, Readie A, Mesenbrink P, Weinstein RS (2010) Efficacy and safety of a once-yearly i.v. infusion of zoledronic acid 5-mg versus a once-weekly 70-mg oral alendronate in the treatment of male osteoporosis: a randomized, multicenter, double-blind, active-controlled study. J Bone Miner Res 25(10):2239-2250 (LoE $\otimes \otimes \otimes \otimes)$

161. Spiegel R, Nawroth PP, Kasperk C (2014) The effect of zoledronic acid on the fracture risk in men with osteoporosis. $\mathrm{J}$ Endocrinol Invest 37(3):229-232 (no LoE)

162. Boonen S, Reginster JY, Kaufman JM, Lippuner K, Zanchetta J, Langdahl B, Rizzoli R, Lipschitz S, Dimai HP, Witvrouw R, Eriksen E, Brixen K, Russo L, Claessens F, Papanastasiou P, Antunez O, Su G, Bucci-Rechtweg C, Hruska J, Incera E, Vanderschueren D, Orwoll E (2012) Fracture risk and zoledronic acid therapy in men with osteoporosis. N Engl J Med 367(18):1714-1723 (LoE $\otimes \otimes \otimes \otimes)$

163. Pepe J, Isidori AM, Falciano M, Iaiani G, Salotti A, Diacinti D, Del Fiacco R, Sbardella E, Cipriani C, Piemonte S, Raimo O, Biondi P, Biamonte F, Lenzi A, Minisola S (2014) Effect of risedronate in osteoporotic HIV males, according to gonadal status: a pilot study. Endocrine 47(2):456-462 (LoE $\otimes \otimes \otimes O)$

164. Orwoll E, Teglbjærg CS, Langdahl BL, Chapurlat R, Czerwinski E, Kendler DL, Reginster JY, Kivitz A, Lewiecki EM,
Miller PD, Bolognese MA, McClung MR, Bone HG, Ljunggren Ö, Abrahamsen B, Gruntmanis U, Yang YC, Wagman RB, Siddhanti S, Grauer A, Hall JW, Boonen S (2012) A randomized, placebo-controlled study of the effects of denosumab for the treatment of men with low bone mineral density. J Clin Endocrinol Metab 97(9):3161-3169 (LoE $\otimes \otimes \otimes \otimes)$

165. Langdahl BL, Teglbjærg CS, Ho PR, Chapurlat R, Czerwinski E, Kendler DL, Reginster JY, Kivitz A, Lewiecki EM, Miller $\mathrm{PD}$, Bolognese MA, McClung MR, Bone HG, Ljunggren Ö, Abrahamsen B, Gruntmanis U, Yang YC, Wagman RB, Mirza F, Siddhanti S, Orwoll E (2015) A 24-month study evaluating the efficacy and safety of denosumab for the treatment of men with low bone mineral density: results from the ADAMO trial. J Clin Endocrinol Metab 100(4):1335-1342 (LoE $\otimes \otimes \otimes \otimes)$

166. Orwoll ES, Scheele WH, Paul S, Adami S, Syversen U, DiezPerez A, Kaufman JM, Clancy AD, Gaich GA (2003) The effect of teriparatide [human parathyroid hormone (1-34)] therapy on bone density in men with osteoporosis. J Bone Miner Res 18(1):9-17 (LoE $\otimes \otimes \otimes \otimes)$

167. Grossmann M, Cheung AS, Zajac JD (2013) Androgens and prostate cancer; pathogenesis and deprivation therapy. Best Pract Res Clin Endocrinol Metab 27(4):603-616 (no LoE)

168. Smith MR (2007) Androgen deprivation therapy for prostate cancer: new concepts and concerns. Curr Opin Endocrinol Diabetes Obes 14(3):247-254 (no LoE)

169. Higano CS (2008) Androgen-deprivation-therapy-induced fractures in men with nonmetastatic prostate cancer: what do we really know? Nat Clin Pract Urol 5(1):24-34 (no LoE)

170. Shahinian VB, Kuo YF, Freeman JL, Goodwin JS (2005) Risk of fracture after androgen deprivation for prostate cancer. $\mathrm{N}$ Engl J Med 352(2):154-164 (LoE $\otimes \otimes \otimes O)$

171. Stoch SA, Parker RA, Chen L, Bubley G, Ko YJ, Vincelette A, Greenspan SL (2001) Bone loss in men with prostate cancer treated with gonadotropin-releasing hormone agonists. J Clin Endocrinol Metab 86(6):2787-2791 (LoE $\otimes \otimes \otimes O)$

172. Greenspan SL, Coates P, Sereika SM, Nelson JB, Trump DL, Resnick NM (2005) Bone loss after initiation of androgen deprivation therapy in patients with prostate cancer. J Clin Endocrinol Metab 90(12):6410-6417 (LoE $\otimes \otimes O O)$

173. Mittan D, Lee S, Miller E, Perez RC, Basler JW, Bruder JM (2002) Bone loss following hypogonadism in men with prostate cancer treated with GnRH analogs. J Clin Endocrinol Metab 87(8):3656-3661 (LoE $\otimes \otimes \otimes O)$

174. Smith MR, Egerdie B, Hernández Toriz N, Feldman R, Tammela TL, Saad F, Heracek J, Szwedowski M, Ke C, Kupic A, Leder BZ, Goessl C, Denosumab HALT Prostate Cancer Study Group (2009) Denosumab in men receiving androgen-deprivation therapy for prostate cancer. N Engl J Med 361(8):745-755 (LoE $\otimes \otimes \otimes \otimes)$

175. Gardner JR, Livingston PM, Fraser SF (2014) Effects of exercise on treatment-related adverse effects for patients with prostate cancer receiving androgen-deprivation therapy: a systematic review. J Clin Oncol 32(4):335-346 (LoE $\otimes \otimes \otimes O$ )

176. Mennen-Winchell LJ, Grigoriev V, Alpert P, Dos Santos H, Tonstad S (2014) Self-reported exercise and bone mineral density in prostate cancer patients receiving androgen deprivation therapy. J Am Assoc Nurse Pract 26(1):40-48 (LoE $\otimes \otimes O O$ )

177. Datta M, Schwartz GG (2012) Calcium and vitamin D supplementation during androgen deprivation therapy for prostate cancer: a critical review. Oncologist 17(9):1171-1179 (no LoE)

178. Alibhai SM, Mohamedali HZ, Gulamhusein H, Panju AH, Breunis H, Timilshina N, Fleshner N, Krahn MD, Naglie G, Tannock IF, Tomlinson G, Warde P, Duff Canning S, Cheung AM (2013) Changes in bone mineral density in men starting androgen deprivation therapy and the protective role of vitamin D. Osteoporos Int 24(10):2571-2579 (LoE $\otimes \otimes \otimes O$ ) 
179. Planas J, Morote J, Orsola A, Salvador C, Trilla E, Cecchini L, Raventós CX (2007) The relationship between daily calcium intake and bone mineral density in men with prostate cancer. BJU Int 99(4):812-815 (LoE $\otimes \otimes O O)$

180. Greenspan SL, Nelson JB, Trump DL, Resnick NM (2007) Effect of once-weekly oral alendronate on bone loss in men receiving androgen deprivation therapy for prostate cancer: a randomized trial. Ann Intern Med 146(6):416-424 (LoE $\otimes \otimes \otimes \otimes)$

181. Serpa Neto A, Tobias-Machado M, Esteves MA, Senra MD, Wroclawski ML, Fonseca FL, Dos Reis RB, Pompeo AC, Giglio AD (2012) Bisphosphonate therapy in patients under androgen deprivation therapy for prostate cancer: a systematic review and meta-analysis. Prostate Cancer Prostatic Dis 15(1):36-44 (LoE $\otimes \otimes \otimes \otimes)$

182. Morgans AK, Smith MR (2012) Bone-targeted agents: preventing skeletal complications in prostate cancer. Urol Clin North Am 39(4):533-546 (no LoE)

183. Saad F, Gleason DM, Murray R, Tchekmedyian S, Venner P, Lacombe L, Chin JL, Vinholes JJ, Goas JA, Chen B, Zoledronic Acid Prostate Cancer Study Group (2002) A randomized, placebo-controlled trial of zoledronic acid in patients with hormone-refractory metastatic prostate carcinoma. J Natl Cancer Inst 94(19): 1458-1468 (LoE $\otimes \otimes \otimes \otimes)$

184. Smith MR, Eastham J, Gleason DM, Shasha D, Tchekmedyian S, Zinner N (2003) Randomized controlled trial of zoledronic acid to prevent bone loss in men receiving androgen deprivation therapy for nonmetastatic prostate cancer. J Urol 169(6):2008$2012(\mathrm{LoE} \otimes \otimes \otimes \otimes)$

185. Klotz LH, McNeill IY, Kebabdjian M, Zhang L, Chin JL, Canadian Urology Research Consortium (2013) A phase 3, doubleblind, randomised, parallel-group, placebo-controlled study of oral weekly alendronate for the prevention of androgen deprivation bone loss in nonmetastatic prostate cancer: the Cancer and Osteoporosis Research with Alendronate and Leuprolide (CORAL) study. Eur Urol 63(5):927-935 (LoE $\otimes \otimes \otimes \otimes) ~$

186. Izumi K, Mizokami A, Sugimoto K, Narimoto K, Kitagawa Y, Koh E, Namiki M (2011) Risedronate prevents persistent bone loss in prostate cancer patients treated with androgen deprivation therapy: results of a 2-year follow-up study. Prostate Cancer Prostatic Dis 14(3):238-242 (LoE $\otimes \otimes \otimes O)$

187. Smith MR, McGovern FJ, Zietman AL, Fallon MA, Hayden DL, Schoenfeld DA, Kantoff PW, Finkelstein JS (2001) Pamidronate to prevent bone loss during androgen-deprivation therapy for prostate cancer. N Engl J Med 345(13):948-955 $(\mathrm{LoE} \otimes \otimes \otimes \otimes)$

188. Morabito N, Gaudio A, Lasco A, Catalano A, Atteritano M, Trifiletti A, Anastasi G, Melloni D, Frisina N (2004) Neridronate prevents bone loss in patients receiving androgen deprivation therapy for prostate cancer. J Bone Miner Res 19(11):1766$1770(\mathrm{LoE} \otimes \otimes \otimes \otimes)$

189. Smith MR, Fallon MA, Lee H, Finkelstein JS (2004) Raloxifene to prevent gonadotropin-releasing hormone agonist-induced bone loss in men with prostate cancer: a randomized controlled trial. J Clin Endocrinol Metab 89(8):3841-3846 (LoE $\otimes \otimes \otimes \otimes)$

190. Smith MR, Morton RA, Barnette KG, Sieber PR, Malkowicz SB, Rodriguez D, Hancock ML, Steiner MS (2010) Toremifene to reduce fracture risk in men receiving androgen deprivation therapy for prostate cancer. J Urol 184(4):1316-1321 (LoE $\otimes \otimes \otimes \otimes)$

191. Khosla S, Lufkin EG, Hodgson SF, Fitzpatrick LA, Melton LJ (1994) Epidemiology and clinical features of osteoporosis in young individuals. Bone 15(5):551-555 ( $\mathrm{LoE} \otimes \otimes \bigcirc \bigcirc)$

192. Peris P, Guanabens N, Martinez de Osaba MJ, Monegal A, Alvarez L, Pons F, Ros I, Cerdá D, Muñoz-Gómez J (2002) Clinical characteristics and etiologic factors of premenopausal osteoporosis in a group of Spanish women. Semin Arthritis Rheum 32(1):64-70 (LoE $\otimes \otimes 00)$

193. Cohen A, Fleischer J, Freeby MJ, McMahon DJ, Irani D, Shane E (2009) Clinical characteristics and medication use among premenopausal women with osteoporosis and low BMD: the experience of an osteoporosis referral center. J Womens Health (Larchmt) 18(1):79-84 (LoE $\otimes \otimes O O)$

194. Sanz-Salvador L, García-Pérez MÁ, Tarín JJ, Cano A (2015) Bone metabolic changes during pregnancy: a period of vulnerability to osteoporosis and fracture. Eur $\mathrm{J}$ Endocrinol 172(2):R53-R65 (no LoE)

195. Lewiecki EM, Gordon CM, Baim S, Binkley N, Bilezikian JP, Kendler DL, Hans DB, Silverman S, Bishop NJ, Leonard MB, Bianchi ML, Kalkwarf HJ, Langman CB, Plotkin H, Rauch F, Zemel BS (2008) Special report on the 2007 adult and pediatric Position Development Conferences of the International Society for Clinical Densitometry. Osteoporos Int 19(10):1369-1378 (no LoE)

196. Bianchi ML (2007) Osteoporosis in children and adolescents. Bone 41(4):486-495 (no LoE)

197. Hosmer WD, Genant HK, Browner WS (2002) Fractures before menopause: a red flag for physicians. Osteoporos Int 13(4):337-341 ( $\mathrm{LoE} \otimes \otimes \otimes O)$

198. Wu F, Mason B, Horne A, Ames R, Clearwater J, Liu M, Evans MC, Gamble GD, Reid IR (2002) Fractures between the ages of 20 and 50 years increase women's risk of subsequent fractures. Arch Intern Med 162(1):33-36 (LoE $\otimes \otimes O O)$

199. Thompson PW, Taylor J, Dawson A (2004) The annual incidence and seasonal variation of fractures of the distal radius in men and women over 25 years in Dorset, UK. Injury 35(5):462$466(\mathrm{LoE} \otimes \otimes \mathrm{OO})$

200. Peris P, Monegal A, Martinez MA, Moll C, Pons F, Guanabens $\mathrm{N}$ (2007) Bone mineral density evolution in young premenopausal women with idiopathic osteoporosis. Clin Rheumatol 26(6):958-961 (LoE $\otimes \otimes O O)$

201. Gatti D, Antoniazzi F, Prizzi R, Braga V, Rossini M, Tatò L, Viapiana O, Adami S (2005) Intravenous neridronate in children with osteogenesis imperfecta: a randomized controlled study. J Bone Miner Res 20(5):758-763 (LoE $\otimes \otimes \otimes \otimes)$

202. Shapiro JR, Thompson CB, Wu Y, Nunes M, Gillen C (2010) Bone mineral density and fracture rate in response to intravenous and oral bisphosphonates in adult osteogenesis imperfecta. Calcif Tissue Int 87(2):120-129 (LoE $\otimes \otimes O O)$

203. Bishop N, Harrison R, Ahmed F, Shaw N, Eastell R, Campbell M, Knowles E, Hill C, Hall C, Chapman S, Sprigg A, Rigby A (2010) A randomized, controlled dose-ranging study of risedronate in children with moderate and severe osteogenesis imperfecta. J Bone Miner Res 25(1):32-40 (LoE $\otimes \otimes \otimes \otimes)$

204. Miller KK, Grieco KA, Mulder J, Grinspoon S, Mickley D, Yehezkel R, Herzog DB, Klibanski A (2004) Effects of risedronate on bone density in anorexia nervosa. J Clin Endocrinol Metab 89(8):3903-3906 (LoE $\otimes \otimes O O)$

205. Pazianas M, Rhim AD, Weinberg AM, Su C, Lichtenstein GR (2006) The effect of anti-TNF-alpha therapy on spinal bone mineral density in patients with Crohn's disease. Ann N Y Acad Sci 1068(4):543-556 (LoE $\otimes \otimes 00)$

206. Papaioannou A, Kennedy CC, Freitag A, Ioannidis G, O’Neill J, Webber C, Pui M, Berthiaume Y, Rabin HR, Paterson N, Jeanneret A, Matouk E, Villeneuve J, Nixon M, Adachi JD (2008) Alendronate once weekly for the prevention and treatment of bone loss in Canadian adult cystic fibrosis patients (CFOS trial). Chest 134(4):794-800 (LoE $\otimes \otimes \otimes \otimes)$

207. Chapman I, Greville H, Ebeling PR, King SJ, Kotsimbos T, Nugent P, Player R, Topliss DJ, Warner J, Wilson JW (2009) Intravenous zoledronate improves bone density in adults with 
cystic fibrosis (CF). Clin Endocrinol (Oxf) 70(6):838-846 (LoE $\otimes \otimes \otimes \otimes)$

208. Conwell LS, Chang AB (2009) Bisphosphonates for osteoporosis in people with cystic fibrosis. Cochrane Database Syst Rev (4): $\mathrm{CD} 002010(\mathrm{LoE} \otimes \otimes \otimes \otimes)$

209. Haidar R, Musallam KM, Taher AT (2011) Bone disease and skeletal complications in patients with beta thalassemia major. Bone 48(3):425-432 (no LoE)

210. Martínez-Morillo M, Grados D, Holgado S (2012) Premenopausal osteoporosis: how to treat? Reumatol Clin 8(2):93-97 (no LoE)

211. Minsker DH, Manson JM, Peter CP (1993) Effects of the bisphosphonate, alendronate, on parturition in the rat. Toxicol Appl Pharmacol 121(2):217-223 (no LoE)

212. Ornoy A, Wajnberg R, Diav-Citrin O (2006) The outcome of pregnancy following pre-pregnancy or early pregnancy alendronate treatment. Reprod Toxicol 22(4):578-579 (LoE $\otimes 000)$

213. Levy S, Fayez I, Taguchi N, Han JY, Aiello J, Matsui D, Moretti M, Koren G, Ito S (2009) Pregnancy outcome following in utero exposure to bisphosphonates. Bone 44(3):428-430 (LoE $\otimes 000)$

214. Odvina CV, Zerwekh JE, Rao DS, Maalouf N, Gottschalk FA, Pak CY (2005) Severely suppressed bone turnover: a potential complication of alendronate therapy. J Clin Endocrinol Metab 90(3):1294-1301 (LoE $\otimes$ O०O)

215. Munns CF, Rauch F, Ward L, Glorieux FH (2004) Maternal and fetal outcome after long-term pamidronate treatment before conception: a report of two cases. J Bone Miner Res 19(10):1742-1745 (LoE $\otimes 000)$

216. Shapiro CL, Manola J, Leboff M (2001) Ovarian failure after adjuvant chemotherapy is associated with rapid bone loss in women with early-stage breast cancer. J Clin Oncol 19(14):3306-3311 (LoE $\otimes \otimes O O)$

217. Gnant M, Mlineritsch B, Luschin-Ebengreuth G, Kainberger F, Kässmann H, Piswanger-Sölkner JC, Seifert M, Ploner F, Menzel C, Dubsky P, Fitzal F, Bjelic-Radisic V, Steger G, Greil R, Marth C, Kubista E, Samonigg H, Wohlmuth P, Mittlböck M, Jakesz R, Austrian Breast and Colorectal Cancer Study Group (ABCSG) (2008) Adjuvant endocrine therapy plus zoledronic acid in premenopausal women with earlystage breast cancer: 5-year follow-up of the ABCSG-12 bonemineral density substudy. Lancet Oncol 9(9):840-849 (LoE $\otimes \otimes \otimes 0)$

218. Eastell R, Adams JE, Coleman RE, Howell A, Hannon RA, Cuzick J, Mackey JR, Beckmann MW, Clack G (2008) Effect of anastrozole on bone mineral density: 5-year results from the anastrozole, tamoxifen, alone or in combination trial 18233230. J Clin Oncol 26(7):1051-1057 (LoE $\otimes \otimes \bigcirc \bigcirc)$

219. Rabaglio M, Sun Z, Price KN, Castiglione-Gertsch M, Hawle H, Thürlimann B, Mouridsen H, Campone M, Forbes JF, Paridaens RJ, Colleoni M, Pienkowski T, Nogaret JM, Láng I, Smith I, Gelber RD, Goldhirsch A, Coates AS, BIG 1-98 Collaborative and International Breast Cancer Study Groups (2009) Bone fractures among postmenopausal patients with endocrineresponsive early breast cancer treated with 5 years of letrozole or tamoxifen in the BIG 1-98 trial. Ann Oncol 20(9):1489-1498 $(\mathrm{LoE} \otimes \otimes \mathrm{O})$

220. Coleman RE, Banks LM, Girgis SI, Kilburn LS, Vrdoljak E, Fox J, Cawthorn SJ, Patel A, Snowdon CF, Hall E, Bliss JM, Coombes RC, Intergroup Exemestane Study group (2007) Skeletal effects of exemestane on bone-mineral density, bone biomarkers, and fracture incidence in postmenopausal women with early breast cancer participating in the Intergroup Exemestane Study (IES): a randomised controlled study. Lancet Oncol 8(2):119-127 (LoE $\otimes \otimes \otimes \otimes)$
221. Howell A, Cuzick J, Baum M, Buzdar A, Dowsett M, Forbes JF, Hoctin-Boes G, Houghton J, Locker GY, Tobias JS, ATAC Trialists' Group (2005) Results of the ATAC (Arimidex, Tamoxifen, Alone or in Combination) trial after completion of 5 years' adjuvant treatment for breast cancer. Lancet 365(9453):60-62 $(\mathrm{LoE} \otimes \otimes \otimes \otimes)$

222. Perez EA, Josse RG, Pritchard KI, Ingle JN, Martino S, Findlay BP, Shenkier TN, Tozer RG, Palmer MJ, Shepherd LE, Liu S, Tu D, Goss PE (2006) Effect of letrozole versus placebo on bone mineral density in women with primary breast cancer completing 5 or more years of adjuvant tamoxifen: a companion study to NCIC CTG MA.17. J Clin Oncol 24(22):3629-3635 $(\mathrm{LoE} \otimes \otimes \bigcirc \mathrm{O})$

223. Cheung AM, Tile L, Cardew S, Pruthi S, Robbins J, Tomlinson G, Kapral MK, Khosla S, Majumdar S, Erlandson M, Scher J, Hu H, Demaras A, Lickley L, Bordeleau L, Elser C, Ingle J, Richardson H, Goss PE (2012) Bone density and structure in healthy postmenopausal women treated with exemestane for the primary prevention of breast cancer: a nested substudy of the MAP.3 randomised controlled trial. Lancet Oncol 13(3):275$284(\mathrm{LoE} \otimes \otimes \otimes \otimes)$

224. Llombart A, Frassoldati A, Paija O, Sleeboom HP, Jerusalem G, Mebis J, Deleu I, Miller J, Schenk N, Neven P (2012) Immediate administration of zoledronic acid reduces aromatase inhibitor-associated bone loss in postmenopausal women with early breast cancer: 12-month analysis of the E-ZO-FAST trial. Clin Breast Cancer 12(1):40-48 (LoE $\otimes \otimes \otimes \otimes)$

225. Brufsky AM, Harker WG, Beck JT, Bosserman L, Vogel C, Seidler C, Jin L, Warsi G, Argonza-Aviles E, Hohneker J, Ericson SG, Perez EA (2012) Final 5-year results of Z-FAST trial: adjuvant zoledronic acid maintains bone mass in postmenopausal breast cancer patients receiving letrozole. Cancer 118(5):1192$1201(\mathrm{LoE} \otimes \otimes \otimes \otimes)$

226. Coleman R, de Boer R, Eidtmann H, Llombart A, Davidson N, Neven P, von Minckwitz G, Sleeboom HP, Forbes J, Barrios C, Frassoldati A, Campbell I, Paija O, Martin N, Modi A, Bundred N (2013) Zoledronic acid (zoledronate) for postmenopausal women with early breast cancer receiving adjuvant letrozole (ZO-FAST study): final 60-month results. Ann Oncol 24(2):398-405 (LoE $\otimes \otimes \otimes \otimes)$

227. Wagner-Johnston ND, Sloan JA, Liu H, Kearns AE, Hines SL, Puttabasavaiah S, Dakhil SR, Lafky JM, Perez EA, Loprinzi CL (2015) 5-year follow-up of a randomized controlled trial of immediate versus delayed zoledronic acid for the prevention of bone loss in postmenopausal women with breast cancer starting letrozole after tamoxifen: N03CC (Alliance) trial. Cancer. doi:10.1002/cncr.29327 (LoE $\otimes \otimes \otimes \otimes)$

228. Van Poznak C, Hannon RA, Mackey JR, Campone M, Apffelstaedt JP, Clack G, Barlow D, Makris A, Eastell R (2010) Prevention of aromatase inhibitor-induced bone loss using risedronate: the SABRE trial. J Clin Oncol 28(6):967-975 (LoE $\otimes \otimes \otimes 0)$

229. Markopoulos C, Tzoracoleftherakis E, Polychronis A, Venizelos B, Dafni U, Xepapadakis G, Papadiamantis J, Zobolas V, Misitzis J, Kalogerakos K, Sarantopoulou A, Siasos N, Koukouras D, Antonopoulou Z, Lazarou S, Gogas H (2010) Management of anastrozole-induced bone loss in breast cancer patients with oral risedronate: results from the ARBI prospective clinical trial. Breast Cancer Res 12(2):R24 (LoE $\otimes \otimes \otimes O)$

230. Sestak I, Singh S, Cuzick J, Blake GM, Patel R, Gossiel F, Coleman R, Dowsett M, Forbes JF, Howell A, Eastell R (2014) Changes in bone mineral density at 3 years in postmenopausal women receiving anastrozole and risedronate in the IBISII bone substudy: an international, double-blind, randomised, placebo-controlled trial. Lancet Oncol 15(13):1460-1468 (LoE $\otimes \otimes \otimes \otimes)$ 
231. Rhee Y, Song K, Park S, Park HS, Lim SK, Park BW (2013) Efficacy of a combined alendronate and calcitriol agent (Maxmarvil $^{\circledR}$ ) in Korean postmenopausal women with early breast cancer receiving aromatase inhibitor: a double-blind, randomized, placebo-controlled study. Endocr J 60(2):167-172 $(\mathrm{LoE} \otimes \otimes \otimes \otimes)$

232. Lester JE, Dodwell D, Purohit OP, Gutcher SA, Ellis SP, Thorpe R, Horsman JM, Brown JE, Hannon RA, Coleman RE (2008) Prevention of anastrozole-induced bone loss with monthly oral ibandronate during adjuvant aromatase inhibitor therapy for breast cancer. Clin Cancer Res 14(19):6336-6342 (LoE $\otimes \otimes \otimes 0)$

233. Valachis A, Polyzos NP, Coleman RE, Gnant M, Eidtmann H, Brufsky AM, Aft R, Tevaarwerk AJ, Swenson K, Lind P, Mauri D (2013) Adjuvant therapy with zoledronic acid in patients with breast cancer: a systematic review and meta-analysis. Oncologist 18(4):353-361 ( $\mathrm{LoE} \otimes \otimes \otimes \otimes)$

234. Ellis GK, Bone HG, Chlebowski R, Paul D, Spadafora S, Smith J, Fan M, Jun S (2008) Randomized trial of denosumab in patients receiving adjuvant aromatase inhibitors for non metastatic breast cancer. J Clin Oncol 26(30):4875-4882 (LoE $\otimes \otimes \otimes \otimes)$

235. Ellis GK, Bone HG, Chlebowski R, Paul D, Spadafora S, Fan M, Kim D (2009) Effect of denosumab on bone mineral density in women receiving adjuvant aromatase inhibitors for nonmetastatic breast cancer: subgroup analyses of a phase 3 study. Breast Cancer Res Treat 118(1):81-87 (LoE $\otimes \otimes \otimes \otimes)$

236. Gnant M, Pfeiler G, Dubsky PC, Hubalek M, Greil R, Jakesz R, Wette V, Balic M, Haslbauer F, Melbinger E, Bjelic-Radisic
V, Artner-Matuschek S, Fitzal F, Marth C, Sevelda P, Mlineritsch B, Steger GG, Manfreda D, Exner R, Egle D, Bergh J, Kainberger F, Talbot S, Warner D, Fesl C, Singer CF, Austrian Breast and Colorectal Cancer Study Group (2015) Adjuvant denosumab in breast cancer (ABCSG-18): a multicentre, randomised, double-blind, placebo-controlled trial. Lancet. doi:10.1016/S0140-6736(15)60995-3 (LoE $\otimes \otimes \otimes \otimes) ~$

237. Reid DM, Doughty J, Eastell R, Heys SD, Howell A, McCloskey EV, Powles T, Selby P, Coleman RE (2008) Guidance for the management of breast cancer treatment-induced bone loss: a consensus position statement from a UK Expert Group. Cancer Treat Rev 34(Suppl 1):S3-S18 (no LoE)

238. Rizzoli R, Body JJ, DeCensi A, Reginster JY, Piscitelli P (2012) Brandi ML; European Society for Clinical and Economical aspects of Osteoporosis and Osteoarthritis (ESCEO). Guidance for the prevention of bone loss and fractures in postmenopausal women treated with aromatase inhibitors for breast cancer: an ESCEO position paper. Osteoporos Int 23(11):2567-2576 (no LoE)

239. Coleman R, Body JJ, Aapro M, Hadji P, Herrstedt J; ESMO Guidelines Working Group (2014) Bone health in cancer patients: ESMO Clinical Practice Guidelines. Ann Oncol 25(Suppl 3): iii124-iii137. (no LoE)

240. AIOM (2013) Linee Guida Trattamento delle Metastasi ossee; Edizione 2013; Prevenzione e trattamento della CTIBL: pagine pp 37-45. (no LoE) 